\title{
Statistical analysis of the main ionospheric trough using Swarm in situ measurements
}

\author{
Ercha $\mathrm{Aa}^{1}$, Shasha Zou ${ }^{2}$, Philip J. Erickson ${ }^{1}$, Shun-Rong Zhang ${ }^{1}$, and Siqing \\ $\mathrm{Liu}^{3}$ \\ ${ }^{1}$ Haystack Observatory, Massachusetts Institute of Technology, Westford, MA, USA \\ ${ }^{2}$ Department of Climate and Space Sciences and Engineering, University of Michigan, Ann Arbor, MI, \\ USA. \\ ${ }^{3}$ National Space Science Center, Chinese Academy of Sciences, Beijing, China.
}

\section{Key Points:}

- The occurrence rate of the main ionospheric trough at 450-550 km exhibits a slight midnight reduction comparing with evening/morning peaks

- The trough has a longitudinal preference with higher occurrence rates in the eastern (western) longitudes around the December (June) solstice

- Conditions for the trough occurrence are more favored in equinoxes than local winter, and in Northern Hemisphere than Southern Hemisphere

This is the author manuscript accepted for publication and has undergone full peer review but has not been through the copyediting, typesetting, pagination and proofreading process, which may lead to differences between this version and the Version of Record. Please cite this article as doi: 10.1029/2019JA027583

Corresponding author: E. Aa, aercha@mit.edu 


\begin{abstract}
A statistical analysis of the topside main ionospheric trough is implemented by using the Swarm constellation in-situ plasma density measurements from December 2013 to November 2019. The key features of the main trough, such as the occurrence rate, minimum position, width, and depth, are characterized and quantified. The distribution patterns of these parameters are investigated with respect to magnetic local time (MLT), season, longitude, solar and geomagnetic activity levels, respectively. The main results are as follows: (1) The diurnal variation of the trough occurrence rate usually exhibits a primary peak in the early morning, a subsidiary peak in the late evening, and a slight reduction around midnight especially in the Northern Hemisphere. (2) The seasonal variation of the nighttime trough has maximum occurrence rates around equinoxes, higher than those in local winter. (3) The trough distribution has an evident hemispherical asymmetry. It is more pronounced in the Northern Hemisphere during the winter and equinoctial seasons, with its average nighttime occurrence rate being $20-30 \%$ higher than that in the Southern Hemisphere. The trough minimum position and the trough width also exhibit more significant fluctuation in the Northern Hemisphere. (4) The longitudinal pattern of the trough shows clear east-west preferences, which has a higher occurrence rate in eastern (western) longitudes around the December (June) solstice. (5) Conditions for the trough occurrence are more favored in low solar activity and high geomagnetic activity periods.
\end{abstract}

\title{
1 Introduction
}

The main ionospheric trough, also referred to as the midlatitude trough, is a typical phenomenon with prominent plasma depletion in the nighttime F-region and topside ionosphere at subauroral latitudes. The main trough lies typically between the footprints of the plasmapause/plasmaspheric boundary layer (Carpenter \& Lemaire, 2004; Pierrard \& Voiculescu, 2011) and the equatorward boundary of the auroral oval, spanning a few degrees in latitude, and is a longitudinally elongated band covering several hours of local time (Moffett \& Quegan, 1983; Rodger et al., 1992). Throughout this paper, the word "trough" refers specifically to the main trough for simplicity. Because the large density gradient in the trough area can significantly affect the propagation of radio signals, understanding the structure and monitoring the dynamics of the trough have an important practical application, especially for trans-ionospheric communication and navigation. Since first identified by a topside sounder (Muldrew, 1965), the trough has been extensively studied for several decades via different instruments and techniques. For example, the trough signature can be captured by in situ plasma measurements from lowEarth orbit satellites, such as the Dynamics Explorer-2 satellite (Rodger et al., 1986; Werner \& Prölss, 1997; Prölss, 2007), Cosmos-900 and Intercosmos-19 satellites (Deminov \& Karpachev, 1986; Afonin et al., 1995; Karpachev et al., 1996, 1998; Karpachev, 2003), Defense Meteorological Satellite Program (DMSP) (Horvath \& Lovell, 2009a, 2009b, 2010; Yang et al., 2016, 2018), and CHAMP satellite (Karpachev et al., 2019; Karpachev, 2019a, 2019b). Moreover, the latitudinal and altitudinal structures of the trough can also be derived from incoherent scatter radars data (e.g., Vo \& Foster, 2001; Nilsson et al., 2005; Voiculescu et al., 2010; Ishida et al., 2014) or radio tomography (Pryse, 2003; Yizengaw \& Moldwin, 2005; Voiculescu et al., 2006; Voiculescu \& Nygrén, 2007). Recently, with the fastgrowing availability of ground-based Global Navigation Satellite Systems (GNSS) total electron content (TEC) data and space-borne radio occultation (RO) observations of the electron density profiles, the temporal and spatial evolution of the trough have been further investigated (e.g., Holt et al., 1983; Mallis \& Essex, 1993; Horvath \& Essex, 2003a; Krankowski et al., 2009a; He et al., 2011; Lee et al., 2011; Zou et al., 2011; Zou, Moldwin, et al., 2013; Yang et al., 2015; Le et al., 2017; Shinbori et al., 2018).

Various mechanisms have been proposed to explain the formation processes of the trough, such as (1) Stagnation mechanism: The westward returning flow within the dusk 
convection cell and the eastward corotating flow with the Earth counteract each other, and the plasma density decays in the quasi-stagnation region due to prolonged recombination in the dark sectors lacking photo-ionization (Spiro et al., 1978; Collis \& Haggstrom, 1988; Nilsson et al., 2005; Rodger, 2008). (2) Increased recombination rate due to enhanced ion temperature: The large poleward electric field associated with the subauroral ion drift (SAID, Spiro et al. (1979)) or subauroral polarization streams (SAPS, Foster and Burke (2002)) can increase the ion temperature via ion-neutral frictional heating and thus accelerate the nonlinear ion loss processes (Schunk et al., 1976; Rodger, 2008; Voiculescu et al., 2016). (3) Field-aligned plasma upflow, which can also be caused by enhanced frictional heating and expansion in the SAID/SAPS region or due to significant ion-neutral relative velocity associated with large meridional neutral winds (Anderson et al., 1991; Voiculescu \& Roth, 2008; Ishida et al., 2014). (4) Precipitation and transportation mechanism: Rodger et al. (1992) pointed out that the trough is the "normal" ionosphere between its poleward and equatorward walls. The poleward wall of the trough is formed mainly by auroral particle precipitation and/or partially by the high-density plasma transportation across the polar cap from the dayside, i.e., boundary blobs (Rodger et al., 1986); the equatorward wall of the trough is formed by the replenishment of plasma from the nightside plasmasphere (Yizengaw \& Moldwin, 2005) and/or built by the sunlit plasma due to corotation (Voiculescu et al., 2010). Overall, it is worthy to note that more than one single mechanism is likely involved in the formation of the trough, and their relative importance accordingly varies with respect to geomagnetic activity conditions. Moreover, the convection flow could transport the decayed plasma into the dayside sector, forming a dayside trough (Whalen, 1989; Rodger et al., 1992; Pryse et al., 1998).

Many statistical analysis and modeling efforts have been made to provide certain insights into the trough characteristics, such as (1) Local time variation: The trough is basically a night-time feature, and the trough minimum position usually occurs at higher latitudes in the afternoon and migrates to lower latitudes with later local times, reaching its equator-most position in the early morning sector (e.g., Ahmed et al., 1979; Oksman, 1982; Grebowsky et al., 1983; Mallis \& Essex, 1993; Werner \& Prölss, 1997; Karpachev, 2003; Rodger, 2008; Krankowski et al., 2009a; Deminov \& Shubin, 2018; Parker et al., 2018; Karpachev, 2019b). (2) Seasonal and hemispheric variation: The afternoon and nighttime trough were observed to be better developed during equinoctial times, and the trough in the winter hemisphere is more prominent with broader width than that in the summer hemisphere (e.g., Horvath \& Essex, 2003a; Voiculescu et al., 2006; Lee et al., 2011). The trough in the Southern Hemisphere summer and equinoctial period sometimes appears on the poleward side of the Weddell Sea anomaly (WSA) and is conjugate with the trough in the winter Northern Hemisphere. In Northern Hemisphere summer, the trough is mainly located at the poleward side of the mid-latitude summer nighttime anomaly (Horvath \& Lovell, 2009b, 2010; Karpachev et al., 2011). (3) Longitudinal effect: The longitudinal variation of the trough position in the wintertime can reach 5- $6^{\circ}$ geomagnetic latitude (MLAT) with considerable hemispheric differences (Karpachev \& Afonin, 1999; Karpachev, 2003). The magnitude of the longitudinal effect of the averaged trough position for a fixed local time is greater in the daytime than that in the nighttime (Karpachev et al., 2019). The longitudinally deepest nighttime trough occurs to the west of the geomagnetic pole in both the Northern and Southern Hemispheres during the equinox seasons and local summer (He et al., 2011). (4) Geomagnetic activity dependence: In general, the trough shifts toward lower latitudes and becomes deeper with increasing geomagnetic activity (e.g., Koehnlein \& Raitt, 1977; Collis \& Haggstrom, 1988; Karpachev et al., 1996; Werner \& Prölss, 1997; Karpachev, 2003; Prölss, 2007; Yang et al., 2016; Le et al., 2017). (5) Solar activity dependence: During low solar activity periods, both daytime and nighttime trough can be much more pronounced than that during high solar activity periods (Karpachev et al., 2019; Karpachev, 2019b), and the trough depth were found to increase with F10.7 index (Ishida et al., 2014; Yang et al., 2015). (6) Interplanetary magnetic field (IMF) dependence: Nighttime troughs are observed more 
frequently when $\mathrm{B}_{y}$ is negative, and more daytime troughs are observed when $\mathrm{B}_{z}$ is negative (Voiculescu et al., 2006; Voiculescu \& Nygrén, 2007). In the Northern hemisphere the vertical and azimuthal IMF components act in opposite phase while in the southern hemisphere the effects of the two components are added (Afonin et al., 1995).

Although significant progress has been achieved through previous studies, the current knowledge of the formation and distribution of the trough is still incomplete, and some critical issues need to be further investigated. For example, many previous studies used the ionospheric NmF2 or total electron content (TEC) data to analyze the trough characteristics, but the actual trough morphology could be more complicated in a 3-dimensional domain. Karpachev (2003) indicated that at low solar activity, the dynamics of both equatorward/poleward walls at high altitudes $(500-1000 \mathrm{~km})$ sharply differs from its dynamics at altitudes of the F2 layer, and the trough depth is higher than that at F2-layer altitudes. Consequently, understanding the trough behavior at a higher altitude can shed more light on the generation and evolution processes of the trough in the topside ionosphere. Furthermore, most studies often deal with the variation of the trough minimum positions. However, very few papers studied the occurrence probability of the trough (Tulunay \& Sayers, 1971; Ahmed et al., 1979; Karpachev, 2019a), and the seasonal distribution of the probability has received less attention (Mallis \& Essex, 1993); some studies are conducted using ground-based observations at specific locations during limited time intervals, while the longitudinal variations of the trough characteristics need to be better specified using successive long-term in situ measurements; many studies focus more on the distribution pattern of the trough in the Northern Hemisphere due to data availability, while the similarities and differences of the trough features between two hemispheres still need to be better specified and explained.

In this study, we use in situ plasma density data measured by the Swarm constellation from December 2013 to November 2019 to statistically analyze the occurrence rate, position, width, and depth of the trough at an altitude of $450-550 \mathrm{~km}$ with respect to different geophysical parameters in both hemispheres. We aim to address the issues as mentioned above and comprehensively investigate the spatial/temporal variability of the trough occurrence and other characteristics. The rest of the paper is organized as follows: the satellite data and the methodology in retrieving the trough are described in section 2. The statistical results of the trough and relevant discussion are given in section 3. The summary and conclusion are presented in section 4 .

\section{Data and Method}

The Swarm constellation consists of three identical satellites (A, B, and C), which were launched on 22 November 2013 into a near-polar low Earth orbit. Swarm A and $\mathrm{C}$ form the lower pair of satellites flying side-by-side (1.4 ${ }^{\circ}$ separation in longitude) at an altitude of $\sim 460 \mathrm{~km}$ with an inclination angle of $87.35^{\circ}$, whereas Swarm B is cruising at a higher orbit of $\sim 520 \mathrm{~km}$ with an inclination angle of $87.75^{\circ}$. Each of the Swarm satellite carries a set of identical scientific instruments. One vital instrument is the Electric Field Instrument, which consists of two Langmuir Probes that can measure the electron density $(\mathrm{Ne})$ at a rate of $2 \mathrm{~Hz}$ (Knudsen et al., 2017). In this study, we use the $\mathrm{Ne}$ data to identify the trough signatures.

From statistical perspective, different algorithms have been used for identifying the trough. Some studies identified the trough region by using the relative density threshold. For example, Ishida et al. (2014) defined the trough region when the minimum density is at least $20 \%$ lower than the background level. Voiculescu et al. (2006) defined the edges of the trough as points where the height-integrated density drops to $50 \%$ from the outside value. Some other studies chose the absolute threshold by visually identifying the trough as the density/TEC minimum within given latitudinal profiles (e.g., Krankowski et al., 2009a; Karpachev et al., 2016; Yang et al., 2016). In our study, the trough iden- 
tification algorithm is described as follows: (1) A 3-point median filter was first applied to remove high-frequency noise, and then continuous time series of $\mathrm{Ne}$ profiles were cut into orbital segments between $45^{\circ}$ and $75^{\circ}$ MLAT for both hemispheres. This latitudinal range approximately covers the position variation of the trough, and a similar range has also been used by other studies (e.g., Lee et al., 2011; Yang et al., 2015). (2) The background density was calculated as the running average of the $N e$ in a sliding window of 480 data points corresponding to a horizontal distance of $\sim 1800 \mathrm{~km}$. This window size was selected by visual inspection and appropriately avoids the influence of significant density irregularities (such as the trough itself) for proper estimation of the background trend. (3) The detrended logarithmic electron density was checked to examine whether it has a negative peak that both corresponds to the local $\mathrm{Ne}$ minimum within the window and lower than a threshold of -0.3 (i.e., $50 \%$ decrease relative to the background level). We also performed a sensitivity analysis and found that the statistical trough characteristics basically did not change while varying this threshold value. (4) After qualifying the threshold requirement, the equatorward and poleward transitions (walls) from the minimum density depletion $\left(\mathrm{T}_{M}\right)$ back to the background $N e$ were marked as $\mathrm{T}_{E}$ and $\mathrm{T}_{P}$, respectively. A width criterion is needed to avoid false reports generated by extensions of small-scale auroral/equatorial plasma irregularities or other large-scale structures. There is no generally consistent threshold of the trough width: the typical value of the trough width is several degrees (Rodger, 2008), while some extremely broad depletion structures can reach $17^{\circ}$ (Karpachev, 2003). Thus, we here set a criterion that if the width between $\mathrm{T}_{E}$ and $\mathrm{T}_{P}$ was larger than $1^{\circ}$ and smaller than $18^{\circ}$, then this density depletion was identified as a trough. The sensitivity analysis also found that only less than $10 \%$ dataset goes beyond $10^{\circ}$, thus the statistical results will not be influenced very much. (5) If more than one trough were identified in a segment, then the equatorward one will be selected as the main trough. A final visual check of the constructed trough database was performed to confirm that more than $95 \%$ assembled cases were correctly identified as troughs, and few misidentified cases such as spontaneous spikes were removed from the data set.

Figure 1 shows an example of the trough identification procedure using two $\mathrm{Ne}$ profiles on 26 August 2018. The left panels show the polar view with a segment of satellite path between geomagnetic latitudes $45^{\circ}$ and $75^{\circ}$ in both hemispheres. The right panels show the latitudinal/temporal variation of the original and detrended $N e$ profiles. The identified trough minimum $\left(\mathrm{T}_{M}\right)$, the equatorward wall $\left(\mathrm{T}_{E}\right)$, and the poleward wall $\left(\mathrm{T}_{p}\right)$ are marked with dots, respectively. In both cases, the trough depletions drastically recovered to the background level with a steep density gradient at the poleward wall, with only gradual recovery on the equatorward side. Additional parameters, such as the poleward (equatorward) half-width, were also extracted as the latitudinal distance between the trough minimum and the poleward (equatorward) wall. After implementing the abovementioned procedures to the Swarm Ne data from December 2013 to November 2019, a dataset that comprised of more than 40,000 troughs in each hemisphere was established, which is large enough to allow a statistical study.

\section{Results and Discussion}

\subsection{Diurnal Variation}

Figures 2a-2c and Figures 3a-3c show the polar distribution of the trough occurrence rate in the coordinates of MLAT versus magnetic local time (MLT) with a resolution of $2^{\circ} \times 0.5 \mathrm{~h}$ for the Northern and Southern Hemispheres, respectively. The results were divided into three periods: the December solstice (November-February), the equinoxes (March, April, September, and October), and the June solstice (May-August). The trough occurrence rate is defined as the ratio of the detected number of trough minimums to the number of satellite crossings in each bin. Figures $2 \mathrm{~d}-2 \mathrm{f}$ and Figures $3 \mathrm{~d}-$ 3f show the corresponding 1D occurrence rate as a function of MLT, which is calculated 
as the ratio of the number of orbits containing the trough to the total available orbits in each MLT sector. Each of the polar plots shows a bright band that is longitudinally extended from dusk to dawn but latitudinally limited mainly between $55^{\circ}$ and $65^{\circ}$, demonstrating that the trough has much higher occurrence rate during the nighttime. Moreover, the shape of the high occurrence band exhibits a considerable seasonal variation. During the wintertime, the peak trough occurrence extends elongates further into higher latitude and earlier MLTs, and has an average nighttime occurrence rate around 50\%$80 \%$ in Northern Hemisphere (Figure 2d) and 40\%-60\% in Southern Hemisphere (Figure 3f). The results indicate that the Northern Hemisphere has more significant trough occurrence rate than that in Southern Hemisphere during their respective wintertime. During the equinoxes, the local time coverage of the trough shrinks slightly while the nighttime occurrence rate still maintains at a similar level to that in the winter. During the summertime, however, the trough occurrence exhibits a very narrow distribution closer to the midnight sector with the occurrence rate being greatly reduced to $\sim 20 \%$, and becomes almost negligible during the daytime (Figures $2 \mathrm{f}$ and $3 \mathrm{~d}$ ).

The diurnal distribution of the trough occurrence rate usually exhibits a primary peak in early morning and a subsidiary peak in late evening, which is consistent with that mentioned in Tulunay and Sayers (1971). Furthermore, it sometimes exhibits a slight reduction around midnight sector comparing with evening and morning peaks, especially during the Northern Hemisphere winter and equinoxes. This phenomenon is in agreement with that mentioned in Rodger et al. (1992) that a boundary between dusk side trough and morning trough should exist due to different flow regimes. On the dusk side, the convection flow changes from eastward to westward from high to low latitude near the Harang reversal region (Harang, 1946; Zou, Lyons, Wang, et al., 2009; Zou, Lyons, Nicolls, et al., 2009; Zou, Lyons, \& Nishimura, 2013), while in the morning sector, the flow is usually eastward. This suggests that troughs at different MLTs might be caused by different physical processes. In the postmidnight/morning sector, there is no flow stagnation. For this reason, part of the postmidnight trough may be the extension of the dusk side one that is slowly convecting and/or corotating towards dawn (Pryse et al., 2006; Rodger, 2008), while Voiculescu and Nygrén (2007) suggested that the postmidnight plasma flow at midlatitude may be so slow that there is sufficient time for recombination to produce a depletion. Moreover, auroral activity usually extends to somewhat lowest latitudes near midnight (Schunk \& Nagy, 2000). Auroral precipitation, combined with the high-density plasma transported by the transpolar convection flow from the dayside, could therefore temporarily fill in plasma decay at the midnight sector to reduce the possibility of trough development (Zou et al., 2011). Although the exact mechanism is not fully clear, our results suggest that on average, the chemical loss process continues to deplete ionospheric plasma in the postmidnight sector.

The bottom panels of Figures 2 and 3 present the average diurnal variation of the trough minimum position during these time periods, with the average trough width and the equatorward/poleward walls being marked. The trough minimum position exhibits a prominent latitudinal variation as a function of MLT for all seasons. It appears at higher latitudes $\left(>70^{\circ}\right)$ around the noontime and gradually migrates to lower latitudes as time passes by. The trough usually reaches its equator-most position $\left(\sim 60^{\circ}\right)$ in the early morning hours ( 03-04 MLT) and then quickly "jumps" back towards higher latitudes forming a discontinuity. We here compared our results with some previous studies that did similar analysis. Voiculescu et al. (2006) also found that there is a morning-side discontinuity in the diurnal variation of the trough latitude, which is in agreement with our results. Karpachev et al. (1998) and Karpachev (2019b) provided similar diurnal patterns of the troughs for different solar activity periods and discussed the relative location of the troughs to the auroral oval. It is known that the main ionospheric trough is located in the equatorward side of the auroral oval (Ahmed et al., 1979), whereas the high latitude trough (HLT) is formed within the auroral oval (Grebowsky et al., 1983). In our study, at nighttime and in the early morning, the troughs are located in relatively 
lower latitudes that below the auroral oval. However, the equatorward boundary of the dayside auroral oval can be highly scattered and blurred in the satellite data, and there are considerable differences between different auroral models' location of this boundary (e.g., Spiro et al., 1982; Hardy et al., 1985; Sotirelis \& Newell, 2000; Carbary, 2005; Landry \& Anderson, 2019). It can be derived from these models that the typical equatorward boundary of the auroral oval during the daytime (09-15 MLT) vary between $70^{\circ}-75^{\circ}$, which is almost collocated with the dayside trough positions in our results. Thus, it cannot be ruled out that the dayside troughs in our results consist of both the main trough and the high latitude trough, although a smooth transition between both phenomena usually exists in the afternoon sector and causes difficulty for attempts to separate them (Werner \& Prölss, 1997). Recently, however, Karpachev (2019b) successfully separated the main trough and the high latitude trough in the late morning sector under high solar activity conditions, and readers may refer to this reference for more details.

For the average nighttime position of the trough minimum, Horvath and Lovell (2009a) and Horvath and Lovell (2009b) found that the nighttime trough developed at geomagnetic latitude around $(62.46 \pm 2.93)^{\circ} \mathrm{N}$ and $(57.60 \pm 2.82)^{\circ} \mathrm{S}$ in the summertime northern and southern hemispheres, respectively. In comparison, our results are slightly different. Tabel 1 shows the average geomagnetic latitudinal position of the trough minimum during 19-05 MLT. The trough minimum appears at a higher latitude in local winter $\left(63.30 \pm 1.45^{\circ} \mathrm{N}\right.$ for Northern Hemisphere and $64.13 \pm 1.52^{\circ} \mathrm{S}$ for Southern Hemisphere) than that in local summer $\left(60.44 \pm 1.25^{\circ} \mathrm{N}\right.$ for Northern Hemisphere and $62.68 \pm 0.91^{\circ} \mathrm{S}$ for Southern Hemisphere). For the trough width, Karpachev (2003) indicated that it becomes shallower and wider in the morning. Our results also indicated that the trough has a narrower width $\left(<5^{\circ}\right)$ in the afternoon, gradually increases closer to midnight, and reaches broadest value $\left(>7^{\circ}\right)$ in the morning sector. Moreover, a considerable seasonal variation can be seen: the equator-most position of the trough minimum appears at a later local time (i.e., more skewed towards morning sector) in winter than that in summer, which occurs in both hemispheres. Furthermore, Lee et al. (2011) indicated that the trough minimum moves back to higher latitudes at a earlier (later) MLT in December solstice (Equinoxes) for the Southern Hemisphere. This asymmetric "V-shape" diurnal distribution pattern is consistent with those indicated in other studies (e.g., Werner \& Prölss, 1997; Krankowski et al., 2009a; Le et al., 2017).

\subsection{Seasonal Variation}

Figure $4 \mathrm{a}$ and $4 \mathrm{~b}$ show the seasonal and local time distribution of the trough occurrence rate for the Northern and Southern Hemispheres, respectively. The resolution is half a month in time and 1 hour in local time (LT), and the occurrence rate is also normalized by the number of satellite crossings in each bin. The white lines represent the location of solar terminator at geomagnetic latitude $\pm 60^{\circ}$. A distinct boundary between daytime and nighttime troughs with a sharp contrast of occurrence rate can be seen, with most of the troughs occurring in nocturnal time at locations that follow the terminator. This phenomenon is consistent with that mentioned in Voiculescu et al. (2006). Moreover, the seasonal distribution pattern of the dayside trough is relatively simple, in that it has the largest occurrence rate in winter and smallest rate in summer since it is strongly related to solar illumination (Karpachev et al., 2019). However, the seasonal variation of the nighttime trough occurrence rate is not yet quite clear, and only a few prior studies have analyzed this with varying and non-uniform results. For example, Mallis and Essex (1993) and Horvath and Essex (2003a) indicated that the nighttime trough in the Southern Hemisphere displays a greater occurrence rate in the vernal equinox and summer than that of winter and autumnal equinox. Voiculescu et al. (2006) found that the autumnal equinox has larger trough occurrence rates than that of winter. These inconsistencies might be partly attributed to the limited number of the trough observations or the uneven spatial/temporal coverage of the instrument measurements. For these rea- 
sons, in the following study, only the quasi-nighttime trough occurring between 19 and 05 LT will be analyzed unless otherwise stated.

Figures $4 \mathrm{c}$ and $4 \mathrm{~d}$ show the seasonal-latitudinal distribution of the nighttime trough occurrence rate with a resolution of half a month in time and $2^{\circ}$ in MLAT, and Figures $4 \mathrm{e}$ and $4 \mathrm{f}$ show the corresponding monthly variation of the nighttime trough occurrence in both hemispheres, respectively. A pronounced seasonal variation can be seen for both hemispheres, in that the nighttime trough is more prominent in wintertime and equinoxes, with its occurrence rate being 3-4 times higher than that in summertime. However, the peak value of the occurrence rate appears not in local winter, but around equinoxes. This may be related to the enhanced auroral activity around the equinoctial months that is collectively generated by: (1) increased solar wind driving conditions when Earth reaches its highest heliographic latitude around equinoxes (Cortie, 1912), (2) an higher-than-average southward component of IMF during equinoctial periods (Russell \& McPherron, 1973), as well as (3) low ionospheric conductivity when the nightside auroral zones of both hemispheres are in darkness (Lyatsky et al., 2001). The enhanced auroral activity will further build-up the poleward wall of the main trough, which would make the trough signatures more easily identified around equinoxes. Also, the ionospheric convection flows are typically enhanced during geomagnetic activities, and thus more troughs are likely to form due to the frictional heating mechanism.

Furthermore, the distribution results in Southern Hemisphere are generally similar to those in Northern Hemisphere with a six-month time shift. However, there is a clear hemispheric asymmetry, in that the seasonal fluctuation of the trough occurrence is more distinct in the Northern Hemisphere than that in the Southern Hemisphere. Under their respective winter and equinoctial periods, the Northern Hemisphere has more significant occurrence rate than that in the Southern Hemisphere, while the opposite is true during their summertime. This might be created by the smaller offset between the geomagnetic and geographic poles in the Northern Hemisphere, which makes the trough zone generally closer to the dark region in the winter/equinoctial time with higher occurrence rate and to the sunlit region in the summertime with lower occurrence rate.

Figures $4 \mathrm{~g}$ show the seasonal variation of the trough minimum positions in both hemispheres, respectively. There is also an apparent seasonal dependence that the trough minimum positions in winter tend to appear at higher latitudes than those in summer, which is also indicated in Table 1. This result agrees with those found in some earlier studies (e.g., Horvath \& Lovell, 2009a; Yang et al., 2015). Furthermore, a clear seasonal variation for the trough width can also be seen in Figure 4h. Both Karpachev (2003) and Voiculescu et al. (2006) indicated that the broadest troughs are observed in winter and the narrowest ones in summer, with the equinox seasons being an intermediate state. Our results show a similar trend with the trough width in the wintertime being $1-2^{\circ}$ wider than the summer case. This can be explained by the poleward extension of the nighttime ionosphere during the wintertime due to the axial rotation tilt of Earth. Moreover, through comparing Table 1 and Figures $4 \mathrm{~g}$ and $4 \mathrm{~h}$, a considerable hemispheric asymmetry for the trough position and width can also be seen with more significant fluctuations existing in the Northern Hemisphere, especially for the trough width. This is similar to the hemispheric asymmetry of trough occurrence rate as mentioned above.

\subsection{Longitudinal Variation}

Besides the diurnal and seasonal variation, many prior studies also indicated that the trough location and its shape exhibit strong longitudinal dependence. For example, Karpachev and Afonin (1999) and Karpachev (2003) found that the longitudinal variation of the trough position in the wintertime can reach 5-6 $6^{\circ}$ MLAT, and the longitudinal variation in two hemispheres behaves differently. Karpachev et al. (2019) found that the longitudinal difference of the nighttime trough position is mainly determined by lon- 
gitudinal variation of auroral particle precipitation, neutral atmosphere composition, and electric field. Furthermore, Karpachev et al. (2011) indicated that the trough in the southern summer period sometimes appears on the poleward side of the Weddell Sea anomaly (WSA) with a strong east-west hemispherical difference, while Horvath and Lovell (2009b) found that the trough in the northern summer is mainly located at the poleward side of the mid-latitude summer nighttime anomaly. Based on these prior results, we here change the coordinates from geomagnetic to geographic to further investigate the longitudinal variation in terms of the trough occurrence rate, position, and width, respectively.

Figure 5 shows the global (a-f) and longitudinal ( $\mathrm{g}-\mathrm{i})$ distribution of the nighttime trough occurrence rate in both hemispheres in geographic coordinates within the latitudinal ranges of $\pm 40^{\circ} \sim \pm 90^{\circ}$ under quiet geomagnetic conditions $(\mathrm{Kp} \leq 3)$ during the December solstice, the equinoxes, and the June solstice, respectively. The resolution is $10^{\circ}$ in longitude and $2^{\circ}$ in latitude, and the occurrence rate is also normalized by the number of satellite crossings in each $2 \mathrm{D}$ bin or $1 \mathrm{D}$ sector. Generally, the high occurrence band aligns well with the geomagnetic latitude of $\pm 62^{\circ}$ represented by red curves, but specific longitudinal preferences can also be seen, with the trough occurrence being more favored in eastern (western) longitudes around December (June) solstice for both hemispheres. Specifically, during the December solstice, the trough has much higher occurrence rate over the Eurasian sector $\left(0^{\circ}-150^{\circ} \mathrm{E}\right)$ for the Northern Hemisphere and over the Indian Ocean sector $\left(60^{\circ}-130^{\circ} \mathrm{E}\right)$ for the Southern Hemisphere. During the June solstice, the trough has relatively higher occurrence rate over the North American sector $\left(90^{\circ}-180^{\circ} \mathrm{W}\right)$ for the Northern Hemisphere and over the Pacific sector $\left(150^{\circ} \mathrm{E}-120^{\circ} \mathrm{W}\right)$ for the Southern Hemisphere.

This longitudinal preference of east-west hemispherical differences can be explained by the illumination differences due to Earth's rotation and the above-mentioned different offsets between the geographic and geomagnetic poles in two hemispheres (He et al., 2011; Karpachev, 2003; Karpachev et al., 2019). Taking the Northern Hemisphere as an example, in winter, the eastern longitudinal (Eurasian) sector along a fixed geomagnetic latitude circle, say $62^{\circ}$, is closer to the full-shadowed polar night region, and thus the trough therein is likely to have a higher occurrence rate. In summer, on the other hand, although the overall occurrence level of the trough is greatly reduced, the western longitudinal (North American) sector tends to have relatively higher occurrence rate due to its location farther apart from the full-illuminated polar day region. In the Southern Hemisphere summer time, there is permanent insolation at geomagnetic latitude of $-62^{\circ}$ between $0^{\circ}$ and $150^{\circ} \mathrm{W}$. Actually, the electron densities over this permanently illuminated region have been observed to maximize around summer nighttime, known as the Weddell Sea Anomaly (Horvath \& Essex, 2003b; Horvath, 2006; Karpachev et al., 2011). Therefore, the trough occurrence rate over this longitudinal region is significantly inhibited as can be seen from Figures $5 \mathrm{~d}$ and $5 \mathrm{~g}$.

Besides the occurrence rate, the magnitude of the trough also has a clear longitudinal variation. Figures $6 \mathrm{a}-6 \mathrm{c}$ show the contour plots of average nighttime in situ $\mathrm{Ne}$ measured by Swarm A/C within the geographic latitudinal ranges of $\pm 40^{\circ} \sim \pm 90^{\circ}$ under quiet geomagnetic conditions $(\mathrm{Kp} \leq 3)$ during different seasons. Figures $6 \mathrm{~d}-6 \mathrm{f}$ display the longitudinal variation of the nighttime $N e$ along the geomagnetic latitude line of $\pm 62^{\circ}$ where the occurrence rate of the trough is high. The results show that the deepest depletion occurs around $130^{\circ} \mathrm{W}$ (marked by red arrows) in the Northern Hemisphere and around $60^{\circ} \mathrm{E}$ (marked by blue arrows) in the Southern Hemisphere for all seasons. Both locations lie to the west of the geomagnetic poles and become wider (narrower) in the winter (summer) time. In addition, a second minor depletion in the Northern Hemisphere occurs between $0-60^{\circ} \mathrm{E}$ during the December solstice and equinoxes. These longitudinal distribution patterns of nighttime trough are consistent with those indicated in $\mathrm{He}$ et al. (2011) and Karpachev et al. (2019) and can be collectively explained by the magnetic field configuration, thermospheric neutral wind, and electric field. 
Additionally, both geomagnetic declination angle and the thermospheric wind could play an essential role in forming the observed trough longitudinal differences (Zhang et al., 2011, 2012). Figure $6 \mathrm{f}$ shows the longitudinal variation of the magnetic declination angle along the geomagnetic latitude line of $\pm 62^{\circ}$. The declination curve in the Northern Hemisphere fluctuates between $\pm 20^{\circ}$ and has double-positive peaks at around $130^{\circ} \mathrm{W}$ and $60^{\circ} \mathrm{E}$, while the declination curve in the Southern Hemisphere has a larger magnitude of $\pm 55^{\circ}$ and reaches its minimum at around $60^{\circ} \mathrm{E}$. Previous measurements indicated that in the midlatitude $\mathrm{F}$ region, the horizontal neutral wind has a maximum eastward component with a minimum northward component in the evening sector (Emmert et al., 2003, 2006). In the Northern Hemisphere, the eastward wind will generate poleward and downward plasma drift where declination is positive, and the downward drift will reduce the plasma density due to higher recombination rate at a lower altitude. In the Southern Hemisphere, on the other hand, downward plasma drift and the density decrease will be favored where declination is negative (He et al., 2011). This is reflected in our trough statistical results. as the plasma density within the trough region accordingly minimizes around $130^{\circ} \mathrm{W}$ and $60^{\circ} \mathrm{E}$ in the Northern Hemisphere and around $60^{\circ} \mathrm{E}$ in the Southern Hemisphere. We note though that these factors do not operate in isolation, and their effects on trough morphology can be mitigated by other processes. For example, Karpachev et al. (2019) indicated that the effect of thermospheric wind could be counteracted to some degree by neutral composition changes and electric field.

Figures $6 \mathrm{~g}-6 \mathrm{l}$ show the longitudinal variation of the nighttime trough minimum position and the trough width for above-mentioned time periods. During the winter and at equinoxes, the trough position usually occurs at a higher latitude in the longitudinal sector that contains the magnetic pole, i.e., in the western longitudinal sector for the Northern Hemisphere and in the eastern longitudinal sectors for the Southern Hemisphere. This phenomenon is consistent with that indicated in Yang et al. (2018) and Karpachev et al. (2019), and can be explained by the longitudinal difference of solar zenith angle. Along a fixed MLAT line, the geographic latitude is relatively lower in the longitudinal sector that contains the magnetic pole. Under the same local time interval, this longitudinal sector tends to have a smaller solar zenith angle and higher ion density, which will compress the low-density trough region and push its equatorward wall into the more poleward area. Thus, the trough width in this longitudinal sector will also be reduced to some extent though the general variation is not significant enough as can be seen in the bottom panels of Figure 6.

\subsection{Solar Activity Dependence}

The Swarm measurements used in the current study cover the descending phase of solar cycle 24. This provides sufficient information to investigate the solar activity dependence of the trough, and Figure 7 shows scatter plots of the monthly averaged trough occurrence rate, trough minimum position, trough width, and trough depth (minimum $\mathrm{Ne}$ subtracted by background value) as a function of F10.7 index for geomagnetic quiet conditions $(\mathrm{Kp} \leq 3)$. The trough occurrence rate and the F10.7 index exhibit a negative correlation with the correlation coefficient reaching a significant level of -0.70 . This is reasonable, as the enhancement of solar extreme ultraviolet (EUV) associated with high solar activity will increase the ionization production rate, thus leading to a decrease in the trough occurrence rate. Moreover, Le et al. (2017) and Karpachev (2019b) indicated that the trough minimum position moves slightly equatorward $\left(1-2^{\circ}\right)$ from low solar activity to high solar activity periods. In Figure $7 \mathrm{~b}$, the correlation between the trough minimum position and the F10.7 index is very weak, though there is also a declining trend between them. A significance analysis further indicated that the uneven data coverage of the Swarm measurements between different solar activity periods will not influence the variation of the trough parameters, thus no clear solar activity dependence of the trough position can be deduced from our preliminary results. In addition, the trough width exhibits a decreasing trend with respect to increasing F10.7 index, while the trough depth 
has a positive correlation with it. This demonstrates that the trough tends to have a deeper and narrower shape during high solar activity periods, which can be explained by enhanced dissociative recombination due to higher ion temperature associated with increasing F10.7 levels (Ishida et al., 2014).

\subsection{Geomagnetic Activity Dependence}

Figure $8 \mathrm{a}$ shows the trough occurrence rate as a function of geomagnetic activity, parameterized by the Kp value. The occurrence rate has a clear increasing trends with respect to increasing $\mathrm{Kp}$ value. In particular, the trough occurrence rate is less than $50 \%$ under quiet conditions $(\mathrm{Kp} \leq 3)$ but is larger than $60 \%$ under active conditions ( $\mathrm{Kp} \geq$ $4)$ ). This clearly suggests that the conditions for trough occurrence are more favorable during high geomagnetic activity periods. Error bars have been added to evaluate possible biases due to uneven data coverage as follows:

$$
\sigma=\sqrt{\frac{f \times(1-f)}{N-1}},
$$

where $\sigma$ is the uncertainty, $f$ is the occurrence rate, and $N$ is the total number of satellite pass for each given bin. Examining these uncertainties, we conclude that although the error bars are also increasing with respect to increasing $\mathrm{Kp}$ value, this does not affect the conclusions we draw.

Figure $8 \mathrm{~b}$ shows the Kp dependence of the trough minimum position. As shown, the trough position moves progressively to a lower latitude as the level of geomagnetic activity increases, which can be approximately fitted by a linear line with the expression as follows: $\mathrm{T}_{M}=65.8^{\circ}-1.7 \mathrm{Kp}$. Here we compare our results with those obtained by Koehnlein and Raitt (1977), Collis and Haggstrom (1988), Karpachev et al. (1996), Horvath and Essex (2003a), Prölss (2007), Yang et al. (2015), and Deminov and Shubin (2018). There is rough agreement between our results and the slope of the fitting lines $(\sim 1.5-2.4)$ from all these studies, though the trough position of the current study seem to be $1^{\circ}-2^{\circ}$ higher than most of the other studies. This slight displacement might be driven by a difference between our study configuration and others, in that our results are derived from the whole quasi-nighttime troughs between 19 and $05 \mathrm{LT}$, while other results shown here are the midnight cases.

The above-mentioned variation of the trough occurrence rate and position with geomagnetic activity level is consistent with other previous studies (e.g., Rodger et al., 1992; Werner \& Prölss, 1997; Pryse et al., 1998; Voiculescu et al., 2006; Krankowski et al., 2009b). This dependence could be partly attributed to the presence of stormtime SAPS/SAID flow channels, which also have a clear Kp dependence. In particular, multiple studies show that the magnetic latitude location of the SAPS peak flow channels moves further equatorward with respect to increasing Kp index (Foster \& Vo, 2002; Erickson et al., 2011; Kunduri et al., 2017). In addition, the magnitude of SAPS flows also increases with Kp index (Goldstein et al., 2005). The flows can exceed 1,500 m/s during geomagnetic storms and drop to $\sim 100 \mathrm{~m} / \mathrm{s}$ during periods of geomagnetic quiet (Kunduri et al., 2018). Considering that SAPS/SAIDs are associated with the formation of a deep mid-latitude ionization trough, their correlation with magnetic activity could be a factor contributing to the geomagnetic dependence of the trough occurrence rate.

Moreover, Figure $8 \mathrm{c}$ and $8 \mathrm{~d}$ show the variation of trough width and depth with respect to the Kp index. The average trough width exhibits a weak decreasing trend as $\mathrm{Kp}$ increases though the fluctuation is less than $1^{\circ}$. On the other hand, the trough depth exhibits a clear increasing trend with increasing $\mathrm{Kp}$ value. This also suggests that enhanced dissociative recombination due to strong frictional heating within stormtime SAPS and/or SAID channels, themselves a hallmark of strong magnetosphere-ionosphere coupling, may represent a primary generation mechanism for the trough formation during large geomagnetic activity conditions. 
One more thing worth noting is that the trough occurrence rate exhibit different dependence with respect to F10.7 and Kp index, though Kp generally tends to be higher with higher solar activity. The explanation might be that corona mass ejection (CME) events that occur more frequently in high solar activity years are more episodic, while the low solar activity years also constitute a large number of samples with medium to high level of Kp associated with recurrent and persistent geomagnetic activities during the declining phase of a solar cycle. In addition, F10.7 also has its inherent 27-day cycles. Thus, their real relationship can be quite intricate, and our statistical study show some complicated F10.7 dependence, not necessarily consistent with the Kp dependence.

\section{Summary and Conclusion}

This paper presents a statistical study of the main ionospheric trough by using in situ plasma density data measured from December 2013 to November 2019 by the Swarm constellation. An automated trough-identifying algorithm and subsequent manual inspection were performed to extract the most typical and prominent cases of the trough. The statistical distribution patterns of various trough characteristics (occurrence rate, position, width, and depth) were investigated with respect to MLT, season, longitude, solar activity, and geomagnetic activity, respectively. The statistical results not only confirmed a number of previously established results using topside ionosphere measurements, but also revealed new trough characteristics, such as longitudinal and hemispheric asymmetries.

To clarify the many study results presented here, those findings that further confirmed previously published results are as follows:

1. The MLT distribution of the trough occurrence rate has a prominent daytime inhibition and a clear nighttime enhancement. The nighttime occurrence rate is approximately three times larger than that in the daytime, with a primary peak in early morning and a subsidiary peak in late evening. The trough appears at relatively higher geomagnetic latitudes $\left(>70^{\circ}\right)$ with narrower width $\left(<4^{\circ}\right)$ in the noon and moves towards lower latitudes during the afternoon and evening hours. It often reaches its equator-most position of $\sim 60^{\circ}$ at around $03-04$ MLT with the broadest width $\left(>7^{\circ}\right)$ and quickly retreats to higher latitudes.

2. The trough distribution has significant seasonal variation. During winter and equinoxes, the longitudinally elongated trough zone with high occurrence rate $(>50 \%)$ extends further into earlier local afternoon sectors. During the summertime, however, the longitudinal extension of the trough is greatly compressed, centering around midnight sector with an average nighttime occurrence rate of only $20 \%$ for both hemispheres. In addition, the nighttime trough position in the winter hemisphere tends to appear at higher geomagnetic latitudes $\left(\sim 65^{\circ}\right)$ with broader width $\left(6^{\circ}-7^{\circ}\right)$, while the trough position and width in the summer hemisphere are usually $3^{\circ}-5^{\circ}$ lower and $1^{\circ}-2^{\circ}$ narrower, respectively.

3. Most of the nighttime trough appears within a latitudinally limited band between $\pm 55^{\circ}-65^{\circ}$ geomagnetic latitudes. The deepest trough is located statistically around $130^{\circ} \mathrm{W}$ in the Northern Hemisphere and around $60^{\circ} \mathrm{E}$ in the Southern Hemisphere, both of which lie to the west of the geomagnetic poles. The trough position usually appears at a relatively higher latitude in the longitudinal sector that contains the magnetic pole.

4. Conditions for the trough occurrence are more favored in low solar activity periods. Both the trough minimum position and trough width have a negative correlation with the F10.7 level, though the dependence of the former one is very weak. The trough depth is positively correlated with the F10.7 level. The trough is highly dependent on geomagnetic activity level with a much higher occurrence rate during active times. The 
trough position moves progressively to lower latitudes as geomagnetic activity increases, and the trough depth exhibits an increasing trend with increasing Kp value.

The new findings of this study on trough morphologies are summarized as follows:

1. The trough occurrence rate exhibits a slight midnight reduction comparing with evening and morning peaks, especially in the Northern Hemisphere. This might be related to the nighttime Harang reversal and/or plasma filling via transpolar convection flow.

2. The seasonal variation of the nighttime trough has a maximum occurrence rate around equinoxes, higher than that in local winter. This might be attributed to the enhanced auroral activity during equinoctial months.

3. The trough distribution has an evident hemispherical asymmetry. During local winter and equinoxes, the trough is more evident in the Northern Hemisphere, with its average nighttime occurrence rate being $20-30 \%$ higher than that in the Southern Hemisphere. Besides, the trough minimum position and the trough width also exhibit more significant fluctuation in the Northern Hemisphere.

4. The longitudinal distribution of the nighttime trough exhibits clear east-west hemispherical preferences. During the December solstice, conditions for the trough occurrence are more favored in eastern longitudes with a higher occurrence rate over the Eurasian sector for the Northern Hemisphere and over the Indian Ocean sector for the Southern Hemisphere. During the June solstice, the western longitudes are more likely to see trough formation with higher occurrence rate over the North American sector for the Northern Hemisphere and over the Pacific sector for the Southern Hemisphere.

Finally, we note that a potential limitation of the current study lies in the use of a fixed threshold to identify the trough ( $50 \%$ decrease relative to the background level). However, the trough can be a highly dynamic phenomenon and in selected cases can pose a considerable challenge in defining uniform and/or robust criteria of identification. In the future, it would be useful to explore techniques from machine learning in an attempt to determine a better way to combine manual inspection methods and automatic processing algorithms. These efforts have scientific potentials to further address the remaining unsolved puzzles of trough behavior and its implications for the overall coupled ionosphere and magnetosphere system. 
Table 1. Average geomagnetic latitudinal position of the trough minimum position between 19-05 MLT.

\begin{tabular}{lcc}
\hline & Northern Hemisphere & Southern Hemisphere \\
\hline Dec. Solstice & $63.30 \pm 1.45^{\circ} \mathrm{N}$ & $62.68 \pm 0.91^{\circ} \mathrm{S}$ \\
Equinoxes & $61.57 \pm 1.38^{\circ} \mathrm{N}$ & $61.56 \pm 1.23^{\circ} \mathrm{S}$ \\
Jun. Solstice & $60.44 \pm 1.25^{\circ} \mathrm{N}$ & $64.13 \pm 1.52^{\circ} \mathrm{S}$ \\
\hline
\end{tabular}



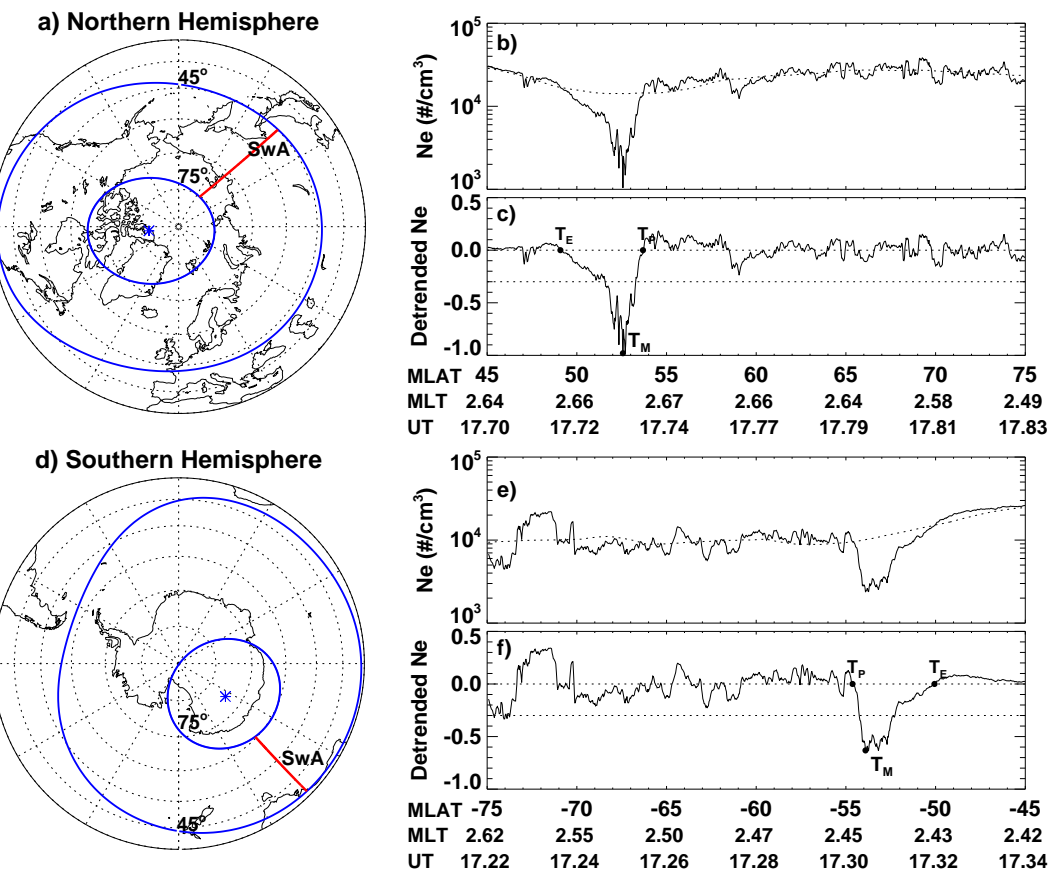

Figure 1. Examples of the trough measured by Swarm A satellite on August 26, 2018. (a) The Northern Hemisphere polar view with a segment of satellite path between geomagnetic latitudes $45^{\circ}$ and $75^{\circ}$. The concentric dashed circles are plotted in $10^{\circ}$ interval. The geomagnetic pole is marked with an asterisk. (b) The corresponding Ne profile as a function of geomagnetic latitude, magnetic local time, and universal time. The dotted line represents the background $\mathrm{Ne}$ profile. (c) Detrended Ne profile with the trough minimum $\left(\mathrm{T}_{M}\right)$, the equatorward wall $\left(\mathrm{T}_{E}\right)$, and the poleward wall $\left(\mathrm{T}_{p}\right)$ being marked. The bottom panels are the same as the upper ones, but for the Southern Hemisphere. 

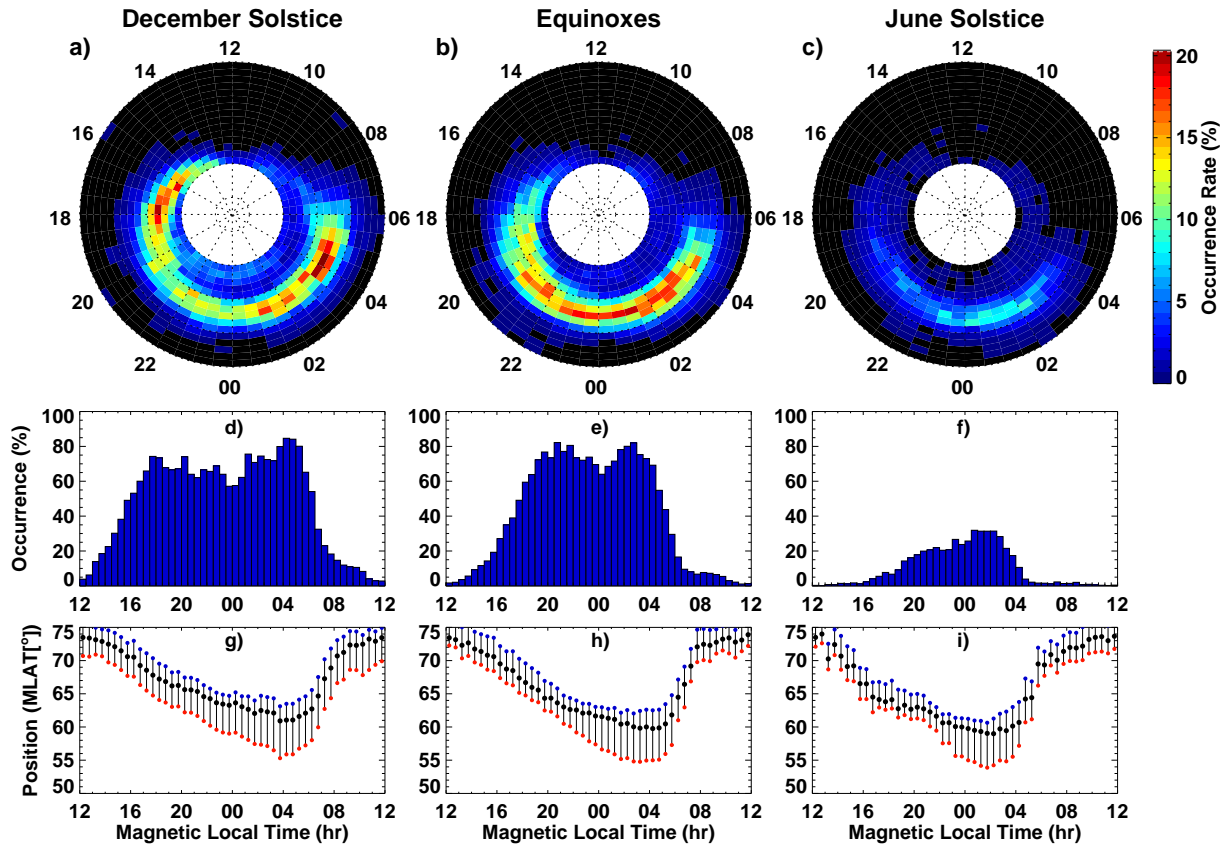

Figure 2. $(\mathrm{a}-\mathrm{c})$ Northern Hemisphere polar view of the trough occurrence rate under quiet geomagnetic conditions $(\mathrm{Kp} \leq 3)$ in the coordinates of magnetic local time and geomagnetic latitude for the December solstice, the equinoxes, and the June solstice, respectively. The concentric circles are plotted in $10^{\circ}$ interval with outermost one representing $45^{\circ}$. Diurnal variation of $(\mathrm{d}-\mathrm{f})$ the trough occurrence rate and ( $\mathrm{g}-\mathrm{i}$ ) the trough minimum position (black dots) as a function of magnetic local time during the above-mentioned three seasons. The bars represent the trough width with the poleward wall (blue dots) and the equatorward wall (red dots) being marked as the two endpoints. 

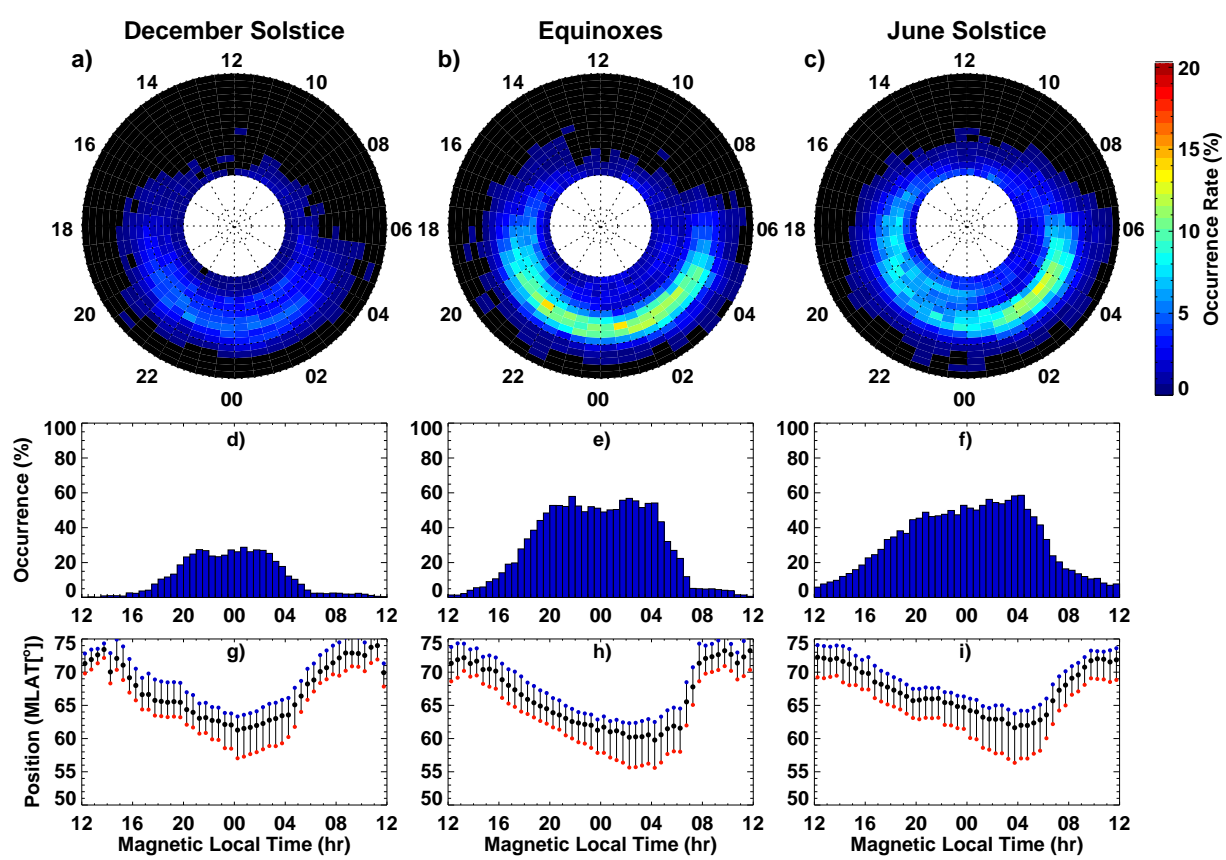

Figure 3. The same as Figure 2, but for the Southern Hemisphere. 


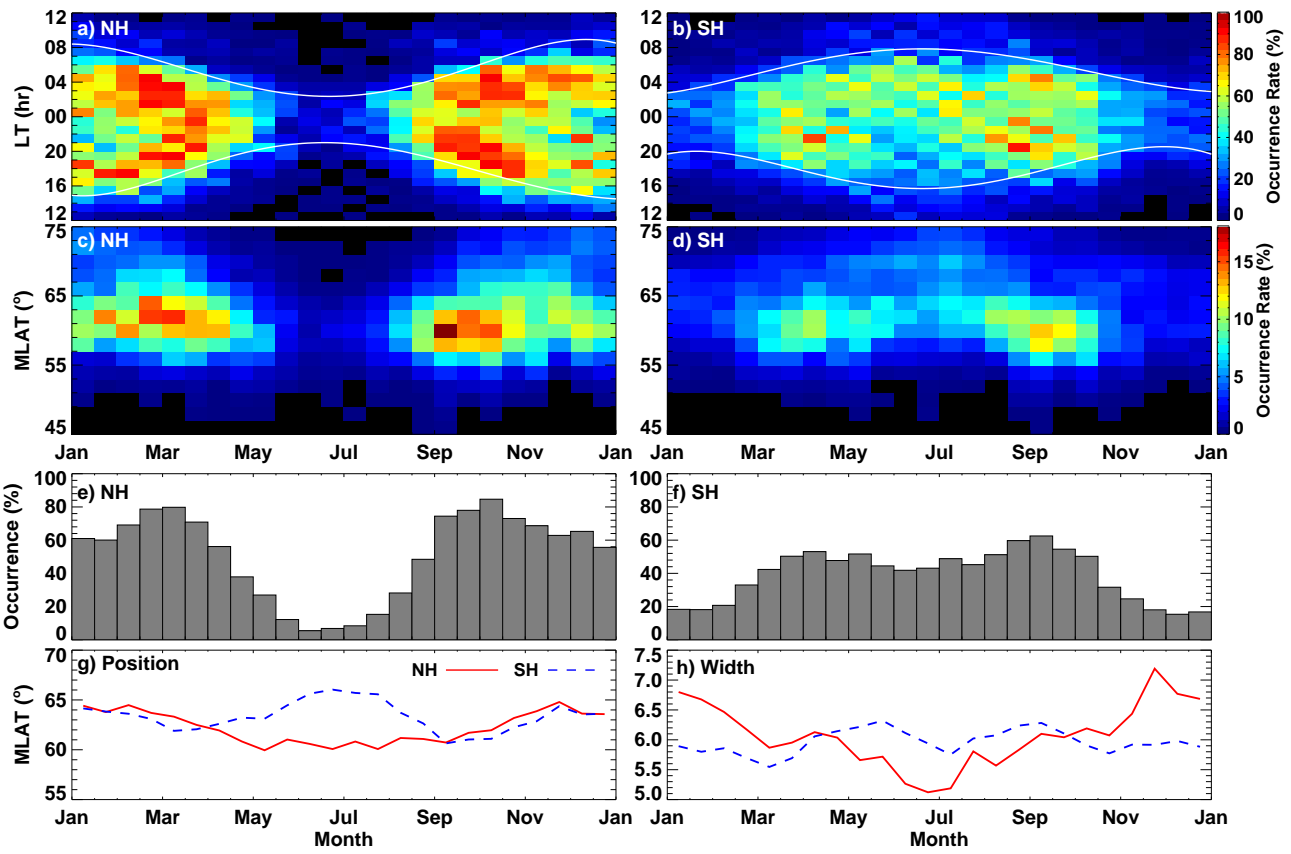

Figure 4. Gridded plots of the trough occurrence rate in terms of (a and b) seasonal-LT distribution and (c and d) seasonal-MLAT distribution for the Northern and Southern hemispheres, respectively. The latitudes in the Southern Hemisphere are rectified for convenience in demonstration. The white lines represent the locations of solar terminator at geomagnetic latitude $60^{\circ} \mathrm{N}$ and $60^{\circ} \mathrm{S}$. The corresponding monthly variation of (e and $\mathrm{f}$ ) the trough occurrence rate, $(\mathrm{g})$ the trough minimum position, and $(\mathrm{h})$ the trough width. $\mathrm{LT}=$ local time; MLAT = geomagnetic latitude. 


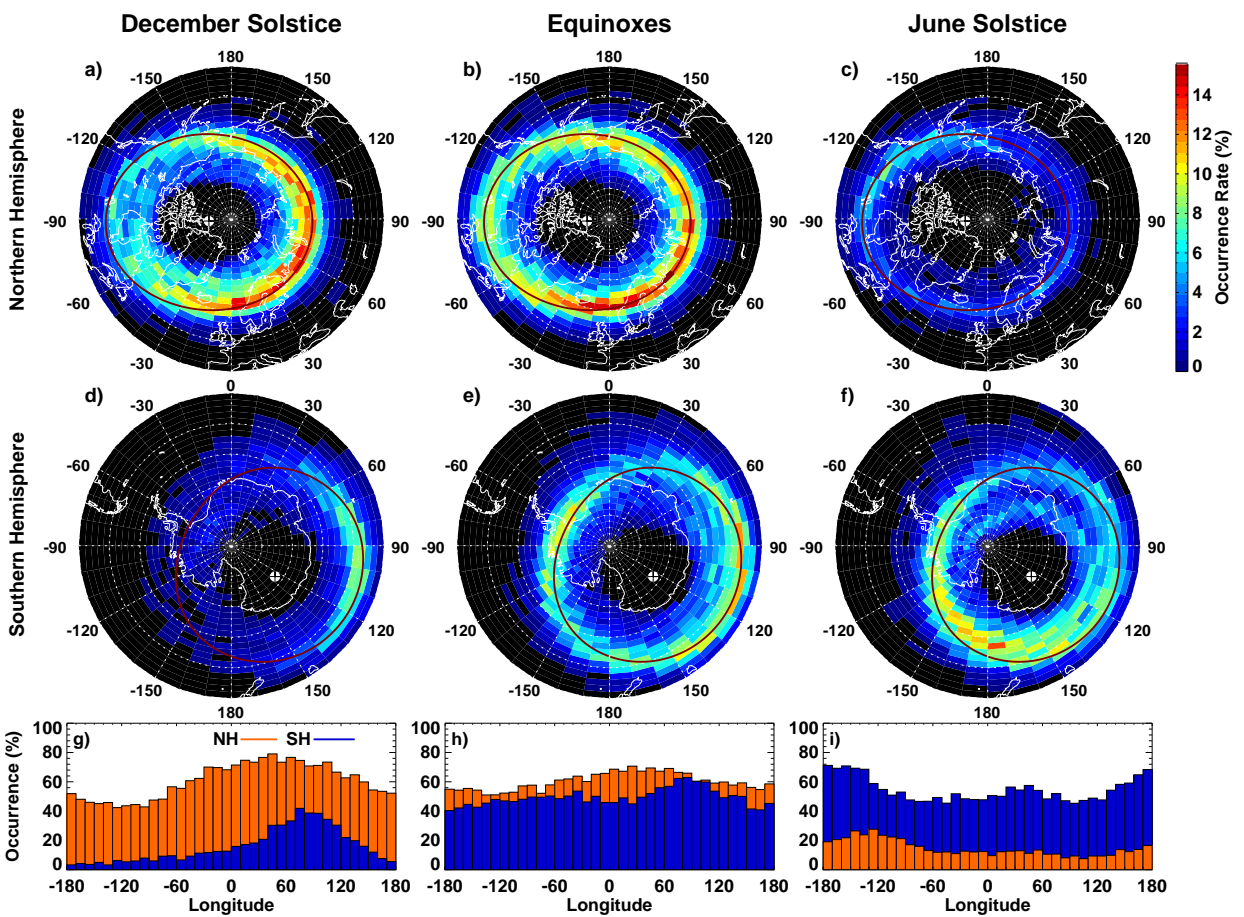

Figure 5. (a-f) Polar view of the trough occurrence rate in the geographic coordinates for both hemispheres under quiet geomagnetic conditions $(\mathrm{Kp} \leq 3)$ during the December solstice, the equinoxes, and the June solstice, respectively. The concentric circles are plotted in $10^{\circ}$ interval with outermost one representing latitude of $40^{\circ}$. The geomagnetic poles are marked with crosses. The geomagnetic latitudes of $\pm 62^{\circ}$ are also plotted in solid red lines. ( $\mathrm{g}-\mathrm{i}$ ) The corresponding longitudinal variation of the trough occurrence rate for above-mentioned conditions. 

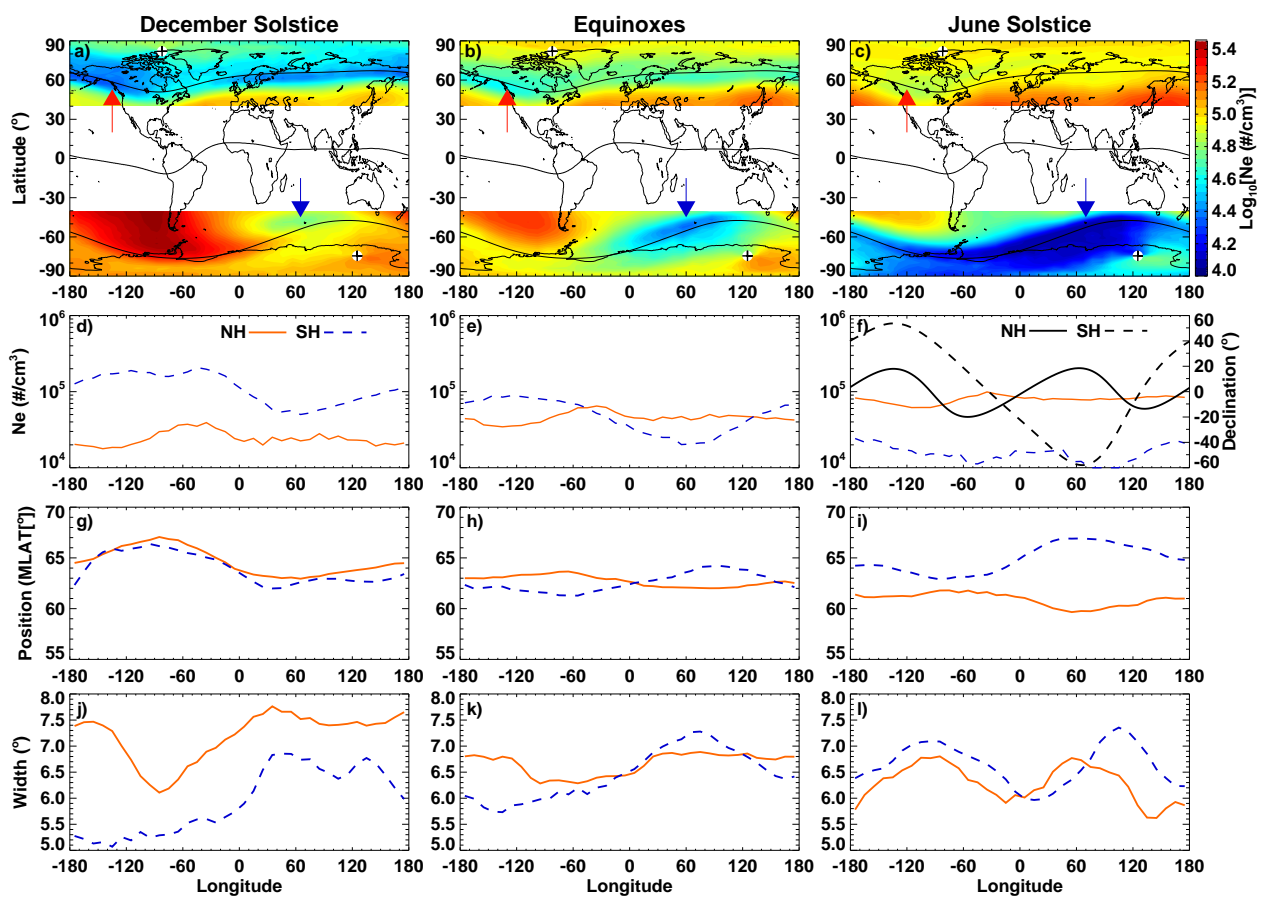

Figure 6. $(\mathrm{a}-\mathrm{c})$ The global distribution of the average $N e$ for both hemispheres under quiet geomagnetic conditions $(\mathrm{Kp} \leq 3)$ during the December solstice, the equinoxes, and the June solstice, respectively. The geomagnetic poles are marked with crosses. The geomagnetic equator and latitudes of $\pm 62^{\circ}$ are plotted in the maps. The red and blue arrows indicate the location of the deepest trough in Northern and Southern Hemispheres, respectively. (d-f) Corresponding longitudinal variation of the $N e$ and magnetic declination (only in the rightmost panel) along geomagnetic latitudes $\pm 62^{\circ}$ lines for above-mentioned conditions. (g-l) Corresponding longitudinal variation of the trough minimum position and the trough width for above-mentioned conditions. 

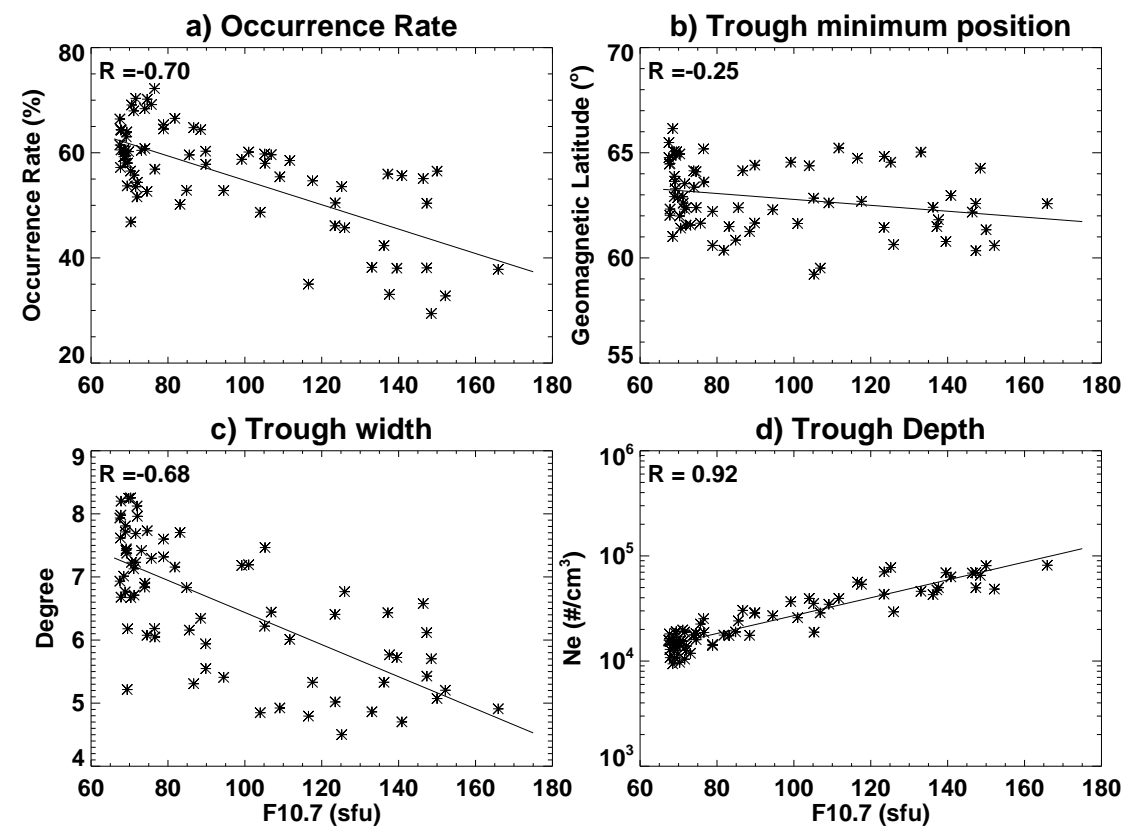

Figure 7. Scatter plots of the monthly averaged F10.7 index versus (a) the trough occurrence rate, (b) the trough minimum position, (c) the trough width, and (d) the trough depth under quiet geomagnetic conditions $(\mathrm{K} p \leq 3)$, respectively. The linear fitted line and the correlation coefficient for each panel are also shown. 
a) Occurrence Rate

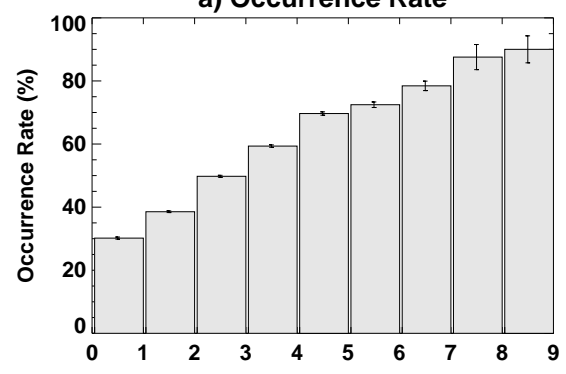

c) Trough Width

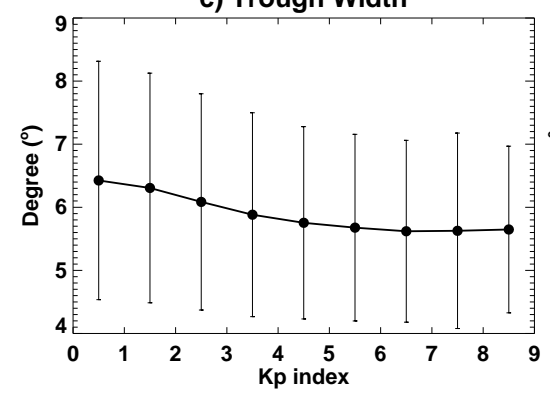

b) Trough Minimum Position

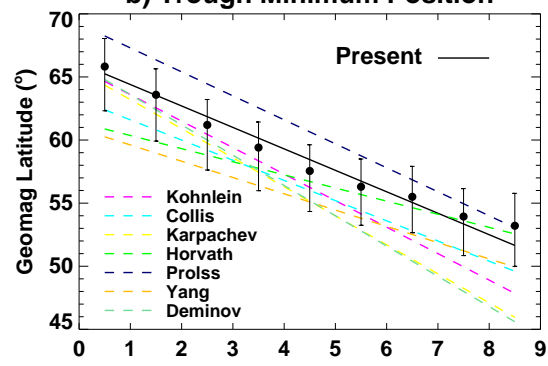

d) Trough Depth

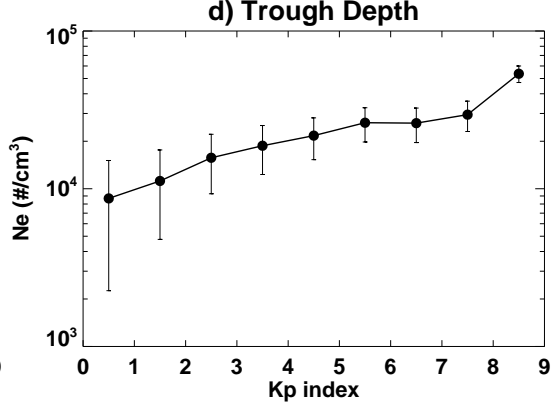

Figure 8. The geomagnetic activity variation of (a) the trough occurrence rate, (b) the trough minimum position, (c) the trough width, and (d) the trough depth as a function of $\mathrm{Kp}$ index with error bars, respectively. Some previous results of the trough minimum position with respect to Kp are also shown: Koehnlein and Raitt (1977, Magnenta), Collis and Haggstrom (1988, Cyan), Karpachev et al. (1996, Yellow), Horvath and Essex (2003a, Green), Prölss (2007, Navy), Yang et al. (2015, Gold), and Deminov and Shubin (2018, Aquamarine).

\section{Acknowledgments}

This work is sponsored by the Strategic Priority Research Program of Chinese Academy of Sciences (XDA17010302), National Key R\&D Program of China (2016YFB0501503), National Science Foundation of China (41674183, 41974184). We greatly acknowledge ESA for providing SWARM data (http://earth.esa.int/swarm). The F10.7 data is acquired from NASA/GSFCs Space Physics Data Facilitys OMNIWeb service (https://cdaweb.gsfc.nasa.gov/). Kp indices are downloaded from Kyoto world data center for Geomagnetism (http://wdc.kugi.kyotou.ac.jp/).

\section{References}

Afonin, V. V., Benkova, N. P., Besprozvannaya, A. S., Shchuka, T. I., Zikrach, E. K., \& Shestakova, L. V. (1995, Jul). The ionospheric trough dynamics in the northern and southern hemispheres: the longitudinal and IMF effect. Journal of Atmospheric and Terrestrial Physics, 57(9), 1057-1062. doi: 10.1016/0021-9169(95)96865-T

Ahmed, M., Sagalyn, R. C., Wildman, P. J. L., \& Burke, W. J. (1979). Topside ionospheric trough morphology: Occurrence frequency and diurnal, seasonal, and altitude variations. Journal of Geophysical Research: Space Physics, 84(A2), 489-498. doi: 10.1029/JA084iA02p00489

Anderson, P. C., Heelis, R. A., \& Hanson, W. B. (1991). The ionospheric signatures of rapid subauroral ion drifts. Journal of Geophysical Research, 96(A4), 57855792. doi: 10.1029/90JA02651

Carbary, J. F. (2005, Oct). A Kp-based model of auroral boundaries. Space 
Weather, 3(10), S10001. doi: 10.1029/2005SW000162

Carpenter, D., \& Lemaire, J. (2004). The Plasmasphere Boundary Layer. Annales Geophysicae, 22(12), 4291-4298. doi: 10.5194/angeo-22-4291-2004

Collis, P. N., \& Haggstrom, I. (1988). Plasma convection and auroral precipitation processes associated with the main ionospheric trough at high latitudes. Journal of Atmospheric and Terrestrial Physics, 50, 389-404. doi: 10.1016/0021-9169(88)90024-4

Cortie, A. L. (1912, Nov). Sun-spots and terrestrial magnetic phenomena, 18981911. Mon. Not. R. Astron. Soc, 73, 52. doi: 10.1093/mnras/73.1.52

Deminov, M. G., \& Karpachev, A. T. (1986, Feb). A longitudinal effect in the configuration of the main ionospheric trough. I - Location of the trough. Geomagnetism and Aeronomy, 26, 63-68.

Deminov, M. G., \& Shubin, V. N. (2018, May). Empirical Model of the Location of the Main Ionospheric Trough. Geomagnetism and Aeronomy, 58(3), 348-355. doi: $10.1134 /$ S0016793218030064

Emmert, J. T., Faivre, M. L., Hernandez, G., Jarvis, M. J., Meriwether, J. W., Niciejewski, R. J., .. Tepley, C. A. (2006). Climatologies of nighttime upper thermospheric winds measured by ground-based Fabry-Perot interferometers during geomagnetically quiet conditions: 1. Local time, latitudinal, seasonal, and solar cycle dependence. Journal of Geophysical Research: Space Physics, 111(A12), A12302. doi: 10.1029/2006JA011948

Emmert, J. T., Fejer, B. G., \& Sipler, D. P. (2003). Climatology and latitudinal gradients of quiet time thermospheric neutral winds over Millstone Hill from Fabry-Perot interferometer measurements. Journal of Geophysical Research: Space Physics, 108(A5), 1196. doi: 10.1029/2002JA009765

Erickson, P. J., Beroz, F., \& Miskin, M. Z. (2011, Mar). Statistical characterization of the American sector subauroral polarization stream using incoherent scatter radar. Journal of Geophysical Research: Space Physics, 116, A00J21. doi: 10.1029/2010JA015738

Foster, J. C., \& Burke, W. J. (2002). SAPS: A new categorization for sub-auroral electric fields. EOS Transactions, 83(36), 393. doi: 10.1029/2002EO000289

Foster, J. C., \& Vo, H. B. (2002, Dec). Average characteristics and activity dependence of the subauroral polarization stream. Journal of Geophysical Research: Space Physics, 107(A12), 1475. doi: 10.1029/2002JA009409

Goldstein, J., Burch, J. L., \& Sandel, B. R. (2005, Sep). Magnetospheric model of subauroral polarization stream. Journal of Geophysical Research: Space Physics, 110 (A9), A09222. doi: 10.1029/2005JA011135

Grebowsky, J. M., Taylor, J., H. A., \& Lindsay, J. M. (1983, Jan). Location and source of ionospheric high latitude troughs. Planetary and Space Science, 31(1), 99-105. doi: 10.1016/0032-0633(83)90034-X

Harang, L. (1946). The mean field of disturbance of polar geomagnetic storms. Terrestrial Magnetism and Atmospheric Electricity, 51(3), 353. doi: 10.1029/ TE051i003p00353

Hardy, D. A., Gussenhoven, M. S., \& Holeman, E. (1985, May). A statistical model of auroral electron precipitation. Journal of Geophysical Research, 90(A5), 4229-4248. doi: 10.1029/JA090iA05p04229

He, M., Liu, L., Wan, W., \& Zhao, B. (2011). A study on the nighttime midlatitude ionospheric trough. Journal of Geophysical Research: Space Physics, 116(A5), A05315. doi: 10.1029/2010JA016252

Holt, J. M., Evans, J. V., \& Wand, R. H. (1983). Millstone Hill studies of the trough - Boundary between the plasmapause and magnetosphere or not? Radio Science, 18, 947-954. doi: 10.1029/RS018i006p00947

Horvath, I. (2006, Dec). A total electron content space weather study of the nighttime Weddell Sea Anomaly of 1996/1997 southern summer with TOPEX/Poseidon radar altimetry. Journal of Geophysical Research (Space 
Physics), 111(A12), A12317. doi: 10.1029/2006JA011679

Horvath, I., \& Essex, E. A. (2003a). The southern-hemisphere mid-latitude day-time and night-time trough at low-sunspot numbers. Journal of Atmospheric and Solar-Terrestrial Physics, 65(8), 917-940. $\quad$ doi: 10.1016/S1364-6826(03)00113 $-5$

Horvath, I., \& Essex, E. A. $\quad$ (2003b, Apr). The Weddell sea anomaly observed with the Topex satellite data. Journal of Atmospheric and Solar-Terrestrial Physics, 65(6), 693-706. doi: 10.1016/S1364-6826(03)00083-X

Horvath, I., \& Lovell, B. C. (2009a, Feb). Investigating the relationships among the South Atlantic Magnetic Anomaly, southern nighttime midlatitude trough, and nighttime Weddell Sea Anomaly during southern summer. Journal of Geophysical Research: Space Physics, 114(A2), A02306. doi: 10.1029/2008JA013719

Horvath, I., \& Lovell, B. C. (2009b). An investigation of the northern hemisphere midlatitude nighttime plasma density enhancements and their relations to the midlatitude nighttime trough during summer. Journal of Geophysical Research: Space Physics, 114(A8), A08308. doi: 10.1029/2009JA014094

Horvath, I., \& Lovell, B. C. (2010, Jan). Investigating the southern daytime midlatitude trough's relation with the daytime Weddell Sea Anomaly during equinoxes. Journal of Geophysical Research: Space Physics, 115(A1), A01302. doi: 10.1029/2008JA014002

Ishida, T., Ogawa, Y., Kadokura, A., Hiraki, Y., \& Häggström, I. ～(2014). Seasonal variation and solar activity dependence of the quiet-time ionospheric trough. Journal of Geophysical Research: Space Physics, 119, 6774-6783. doi: 10.1002/2014JA019996

Karpachev, A. T. (2003). The dependence of the main ionospheric trough shape on longitude, altitude, season, local time, and solar and magnetic activity. Geomagnetism and Aeronomy, 43(2), 239-251.

Karpachev, A. T. (2019a, Jul). Model of the Ionospheric Trough for Daytime Winter Conditions Based on Data from Interkosmos-19 and Champ Satellites. Geomagnetism and Aeronomy, 59(4), 383-397. doi: 10.1134/S0016793219040091

Karpachev, A. T. (2019b). Variations in the Winter Troughs' Position With Local Time, Longitude, and Solar Activity in the Northern and Southern Hemispheres. Journal of Geophysical Research: Space Physics, 124(10), 8039-8055. doi: 10.1029/2019JA026631

Karpachev, A. T., \& Afonin, V. V. (1999). Longitudinal variations in the positions of daytime winter ionospheric troughs. Geomagnetism and Aeronomy, 39(2), 194-200.

Karpachev, A. T., Deminov, M. G., \& Afonin, V. V. (1996, Jan). Model of the mid-latitude ionospheric trough on the base of Cosmos-900 and Intercosmos19 satellites data. Advances in Space Research, 18(6), 221-230. doi: 10.1016/0273-1177(95)00928-0

Karpachev, A. T., Deminov, M. G., \& Afonin, V. V. (1998, Jan). Two branches of day-time winter ionospheric trough according to cosmos-900 data at F2-layer heights. Advances in Space Research, 22(6), 877-882. doi: 10.1016/S0273-1177(98)00117-3

Karpachev, A. T., Gasilov, N. A., \& Karpachev, O. A. (2011, Dec). Morphology and causes of the Weddell Sea anomaly. Geomagnetism and Aeronomy, 51(6), 812824. doi: $10.1134 /$ S0016793211050070

Karpachev, A. T., Klimenko, M. V., \& Klimenko, V. V. (2019). Longitudinal variations of the ionospheric trough position. Advances in Space Research, 63(2), 950-966. doi: 10.1016/j.asr.2018.09.038

Karpachev, A. T., Klimenko, M. V., Klimenko, V. V., \& Pustovalova, L. V. (2016). Empirical model of the main ionospheric trough for the nighttime winter conditions. Journal of Atmospheric and Solar-Terrestrial Physics, 146, 149-159. doi: $10.1016 /$ j.jastp.2016.05.008 
Knudsen, D. J., Burchill, J. K., Buchert, S. C., Eriksson, A. I., Gill, R., Wahlund, J. E., ... Moffat, B. (2017). Thermal ion imagers and Langmuir probes in the Swarm electric field instruments. Journal of Geophysical Research: Space Physics, 122(2), 2655-2673. doi: 10.1002/2016JA022571

Koehnlein, W., \& Raitt, W. J. $\quad$ (1977, Jun). Position of the mid-latitude trough in the topside ionosphere as deduced from ESRO 4 observations. Planet. Space Sci, 25(6), 600-602. doi: 10.1016/0032-0633(77)90069-1

Krankowski, A., Shagimuratov, I. I., Ephishov, I. I., Krypiak-Gregorczyk, A., \& Yakimova, G. (2009a). The occurrence of the mid-latitude ionospheric trough in GPS-TEC measurements. Advances in Space Research, 43(11), 1721-1731. doi: $10.1016 /$ j.asr.2008.05.014

Krankowski, A., Shagimuratov, I. I., Ephishov, I. I., Krypiak-Gregorczyk, A., \& Yakimova, G. (2009b). The occurrence of the mid-latitude ionospheric trough in GPS-TEC measurements. Advances in Space Research, 43(11), 1721-1731. doi: 10.1016/j.asr.2008.05.014

Kunduri, B. S. R., Baker, J. B. H., Ruohoniemi, J. M., Nishitani, N., Oksavik, K., Erickson, P. J., ... Miller, E. S. (2018, Sep). A New Empirical Model of the Subauroral Polarization Stream. Journal of Geophysical Research: Space Physics, 123(9), 7342-7357. doi: 10.1029/2018JA025690

Kunduri, B. S. R., Baker, J. B. H., Ruohoniemi, J. M., Thomas, E. G., Shepherd, S. G., \& Sterne, K. T. (2017, Jun). Statistical characterization of the largescale structure of the subauroral polarization stream. Journal of Geophysical Research: Space Physics, 122(6), 6035-6048. doi: 10.1002/2017JA024131

Landry, R. G., \& Anderson, P. C. (2019, Mar). Empirical Modeling of the Equatorward Boundary of Auroral Precipitation Using DMSP and DE 2. Journal of Geophysical Research: Space Physics, 124(3), 2072-2082. doi: 10.1029/2018JA025451

Le, H., Yang, N., Liu, L., Chen, Y., \& Zhang, H. (2017). The latitudinal structure of nighttime ionospheric TEC and its empirical orthogonal functions model over North American sector. Journal of Geophysical Research: Space Physics, 122(1), 963-977. doi: 10.1002/2016JA023361

Lee, I. T., Wang, W., Liu, J. Y., Chen, C. Y., \& Lin, C. H. (2011). The ionospheric midlatitude trough observed by FORMOSAT-3/COSMIC during solar minimum. Journal of Geophysical Research: Space Physics, 116(A6), A06311. doi: 10.1029/2010JA015544

Lyatsky, W., Newell, P. T., \& Hamza, A. (2001, Jan). Solar illumination as cause of the equinoctial preference for geomagnetic activity. Geophysical Research Letters, 28(12), 2353-2356. doi: 10.1029/2000GL012803

Mallis, M., \& Essex, E. A. (1993, Jun). Diurnal and seasonal variability of the Southern-Hemisphere main ionospheric trough from differential-phase measurements. Journal of Atmospheric and Terrestrial Physics, 55(7), 1021-1037. doi: 10.1016/0021-9169(93)90095-G

Moffett, R. J., \& Quegan, S. (1983). The mid-latitude trough in the electron concentration of the ionospheric F-layer - A review of observations and modelling. Journal of Atmospheric and Terrestrial Physics, 45, 315-343. doi: 10.1016/S0021-9169(83)80038-5

Muldrew, D. B. (1965). F-Layer Ionization Troughs Deduced from Alouette Data. Journal of Geophysical Research, 70(11), 2635-2650. doi: 10.1029/JZ070i011p02635

Nilsson, H., Sergienko, T. I., Ebihara, Y., \& Yamauchi, M. （2005). Quiettime mid-latitude trough: influence of convection, field-aligned currents and proton precipitation. Annales Geophysicae, 23(10), 3277-3288. doi: 10.5194/angeo-23-3277-2005

Oksman, J. (1982). Apparent diurnal movements of the trough in total electron content (TEC) of the ionosphere. Geophysica, 19(1), 13-22. 
Parker, J., Eleri Pryse, S., Jackson-Booth, N., \& Buckland, R. (2018). Modelling the main ionospheric trough using the Electron Density Assimilative Model (EDAM) with assimilated GPS TEC. Annales Geophysicae, 36(1), 125-138. doi: 10.5194/angeo-36-125-2018

Pierrard, V., \& Voiculescu, M. (2011, Jun). The 3D model of the plasmasphere coupled to the ionosphere. Geophysical Research Letters, 38(12), L12104. doi: 10 $.1029 / 2011$ GL047767

Prölss, G. W. (2007, Mar). The equatorward wall of the subauroral trough in the afternoon/evening sector. Annales Geophysicae, 25(3), 645-659. doi: 10.5194/ angeo-25-645-2007

Pryse, S. E. (2003). Radio Tomography: A New Experimental Technique. Surveys in Geophysics, 24(1), 1-38.

Pryse, S. E., Kersley, L., Malan, D., \& Bishop, G. J. (2006). Parameterization of the main ionospheric trough in the European sector. Radio Science, 41(5), RS5S14. doi: 10.1029/2005RS003364

Pryse, S. E., Kersley, L., Williams, M. J., \& Walker, I. K. (1998). The spatial structure of the dayside ionospheric trough. Annales Geophysicae, 16(10), 1169-1179. doi: 10.1007/s00585-998-1169-4

Rodger, A. S. (2008). The mid-latitude trough-Revisited. Washington DC American Geophysical Union Geophysical Monograph Series, 181, 25-33. doi: 10.1029/181GM04

Rodger, A. S., Brace, L. H., Hoegy, W. R., \& Winningham, J. D. (1986). The poleward edge of the mid-latitude trough - Its formation, orientation and dynamics. Journal of Atmospheric and Terrestrial Physics, 48, 715-728. doi: 10.1016/0021-9169(86)90021-8

Rodger, A. S., Moffett, R. J., \& Quegan, S. (1992). The role of ion drift in the formation of ionisation troughs in the mid- and high-latitude ionosphere -

a review. Journal of Atmospheric and Terrestrial Physics, 54, 1-30. doi: 10.1016/0021-9169(92)90082-V

Russell, C. T., \& McPherron, R. L. (1973, Jan). Semiannual variation of geomagnetic activity. Journal of Geophysical Research, 78(1),92. doi: 10.1029/JA078i001p00092

Schunk, R. W., Banks, P. M., \& Raitt, W. J. (1976). Effects of electric fields and other processes upon the nighttime high-latitude F layer. Journal of Geophysical Research, 81 (19), 3271. doi: 10.1029/JA081i019p03271

Schunk, R. W., \& Nagy, A. F. (2000). Ionospheres: physics, plasma physics, and chemistry. Cambridge University Press.

Shinbori, A., Otsuka, Y., Tsugawa, T., Nishioka, M., Kumamoto, A., Tsuchiya, F., .. Nishitani, N. (2018, Aug). Temporal and Spatial Variations of Storm Time Midlatitude Ionospheric Trough Based on Global GNSS-TEC and Arase Satellite Observations. Geophysical Research Letters, 45(15), 7362-7370. doi: 10.1029/2018GL078723

Sotirelis, T., \& Newell, P. T. (2000). Boundary-oriented electron precipitation model. Journal of Geophysical Research: Space Physics, 105(A8), 18655-18673. doi: 10.1029/1999JA000269

Spiro, R. W., Heelis, R. A., \& Hanson, W. B. (1978). Ion convection and the formation of the mid-latitude $\mathrm{F}$ region ionization trough. Journal of Geophysical Research, 83(A9), 4255-4264. doi: 10.1029/JA083iA09p04255

Spiro, R. W., Heelis, R. A., \& Hanson, W. B. (1979). Rapid subauroral ion drifts observed by Atmosphere Explorer C. Geophysical Research Letters, 6(8), 657660. doi: 10.1029/GL006i008p00657

Spiro, R. W., Reiff, P. H., \& Maher, J., L. J. (1982, Oct). Precipitating electron energy flux and auroral zone conductances-an empirical model. Journal of Geophysical Research, 87(A10), 8215-8227. doi: 10.1029/JA087iA10p08215

Tulunay, Y. K., \& Sayers, J. (1971, Nov). Characteristics of the mid-latitude 
trough as determined by the electron density experiment on Ariel III.

Journal of Atmospheric and Terrestrial Physics, 33(11), 1737-1761.

doi: 10.1016/0021-9169(71)90221-2

Vo, H. B., \& Foster, J. C. (2001). A quantitative study of ionospheric density gradients at midlatitudes. Journal of Geophysical Research, 106(A10), 21555-21564. doi: 10.1029/2000JA000397

Voiculescu, M., \& Nygrén, T. (2007). IMF effect on ionospheric trough occurrence at equinoxes. Advances in Space Research, 40(12), 1935-1940. doi: 10.1016/j.asr .2007.04.108

Voiculescu, M., Nygrén, T., Aikio, A., \& Kuula, R. (2010). An olden but golden EISCAT observation of a quiet-time ionospheric trough. Journal of Geophysical Research: Space Physics, 115(A10), A10315. doi: 10.1029/2010JA015557

Voiculescu, M., Nygrén, T., Aikio, A. T., Vanhamäki, H., \& Pierrard, V. (2016). Postmidnight ionospheric troughs in summer at high latitudes. Journal of Geophysical Research: Space Physics, 121(12), 12,171-12,185. doi: 10.1002/2016JA023360

Voiculescu, M., \& Roth, M. (2008, Jul). Eastward sub-auroral ion drifts or ASAID. Annales Geophysicae, 26(7), 1955-1963. doi: 10.5194/angeo-26-1955-2008

Voiculescu, M., Virtanen, I., \& Nygrén, T. (2006). The F-region trough: seasonal morphology and relation to interplanetary magnetic field. Annales Geophysicae, 24 (1), 173-185. doi: 10.5194/angeo-24-173-2006

Werner, S., \& Prölss, G. W. (1997). The position of the ionospheric trough as a function of local time and magnetic activity. Advances in Space Research, 20 (9), 1717-1722. doi: 10.1016/S0273-1177(97)00578-4

Whalen, J. A. (1989). The daytime F layer trough and its relation to ionosphericmagnetospheric convection. Journal of Geophysical Research, 94(A12), 1716917184. doi: 10.1029/JA094iA12p17169

Yang, N., Le, H., \& Liu, L. (2015). Statistical analysis of ionospheric mid-latitude trough over the Northern Hemisphere derived from GPS total electron content data. Earth, Planets, and Space, 67, 196. doi: 10.1186/s40623-015-0365-1

Yang, N., Le, H., \& Liu, L. (2016). Statistical analysis of the mid-latitude trough position during different categories of magnetic storms and different storm intensities. Earth, Planets, and Space, 68(1), $171 . \quad$ doi: 10.1186/s40623-016-0554-6

Yang, N., Le, H., Liu, L., \& Zhang, R. (2018). Statistical Behavior of the Longitudinal Variations of the Evening Topside Mid-Latitude Trough Position in both Northern and Southern Hemispheres. Journal of Geophysical Research: Space Physics, 123(5), 3983-3997. doi: 10.1029/2017JA025048

Yizengaw, E., \& Moldwin, M. (2005). The altitude extension of the mid-latitude trough and its correlation with plasmapause position. Geophysical Research Letters, 32(9), L09105. doi: 10.1029/2005GL022854

Zhang, S.-R., Foster, J. C., Coster, A. J., \& Erickson, P. J. (2011). East-West Coast differences in total electron content over the continental US. Geophysical Research Letters, 38(19), L19101. doi: 10.1029/2011GL049116

Zhang, S.-R., Foster, J. C., Holt, J. M., Erickson, P. J., \& Coster, A. J. (2012). Magnetic declination and zonal wind effects on longitudinal differences of ionospheric electron density at midlatitudes. Journal of Geophysical Research: Space Physics, 117(A8), A08329. doi: 10.1029/2012JA017954

Zou, S., Lyons, L. R., Nicolls, M. J., Heinselman, C. J., \& Mende, S. B. $\quad$ (2009). Nightside ionospheric electrodynamics associated with substorms: PFISR and THEMIS ASI observations. Journal of Geophysical Research: Space Physics, 114(A12), A12301. doi: 10.1029/2009JA014259

Zou, S., Lyons, L. R., \& Nishimura, Y. (2013). Mutual evolution of aurora and ionospheric electrodynamic features near the harang reversal during substorms. In Auroral phenomenology and magnetospheric processes: Earth 
and other planets (p. 159-170). American Geophysical Union (AGU). doi: 10.1029/2011GM001163

Zou, S., Lyons, L. R., Wang, C. P., Boudouridis, A., Ruohoniemi, J. M., Anderson, P. C., ... Devlin, J. C. (2009). On the coupling between the Harang reversal evolution and substorm dynamics: A synthesis of SuperDARN, DMSP, and IMAGE observations. Journal of Geophysical Research: Space Physics, 114(A1), A01205. doi: 10.1029/2008JA013449

Zou, S., Moldwin, M., Coster, A., Lyons, L., \& Nicolls, M. (2011). GPS TEC observations of dynamics of the mid-latitude trough during substorms. Geophysical Research Letters, 38(14), L14109. doi: 10.1029/2011GL048178

Zou, S., Moldwin, M. B., Nicolls, M. J., Ridley, A. J., Coster, A. J., Yizengaw, E., ... Donovan, E. F. (2013, May). Electrodynamics of the high-latitude trough: Its relationship with convection flows and field-aligned currents. Journal of Geophysical Research: Space Physics, 118(5), 2565-2572. doi: 10.1002/jgra.50120 

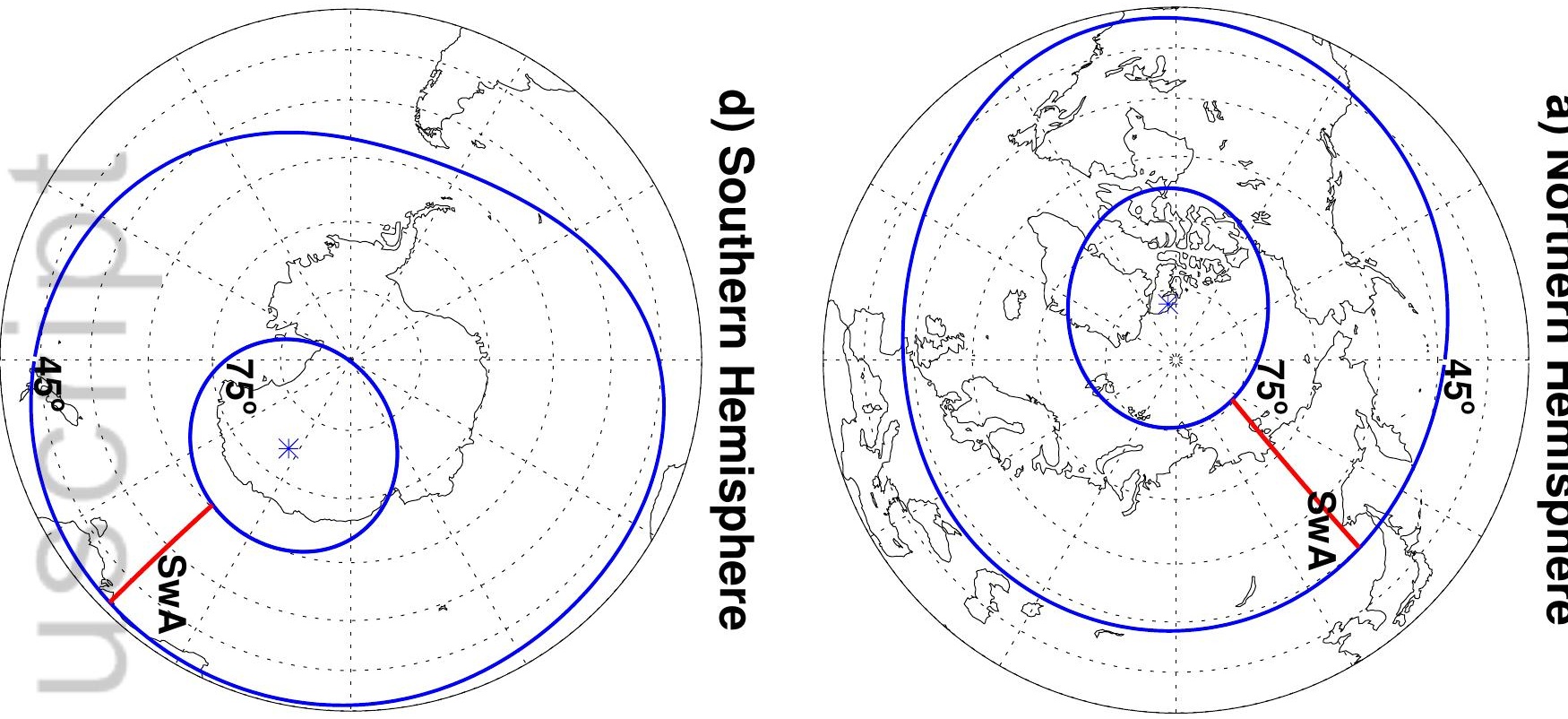

Detrended $\mathrm{Ne} \mathrm{Ne}\left(\# / \mathrm{cm}^{3}\right) \quad \subsetneq 3$ Detrended $\mathrm{Ne} \mathrm{Ne}\left(\# / \mathrm{cm}^{3}\right)$

ò

蕠宛

.

용

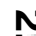

今ें

$3 \sum_{3}^{2}$

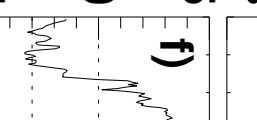

N

$\tilde{\omega} \dot{\omega}$ $\vec{s}$

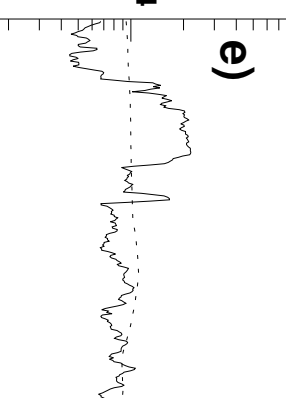

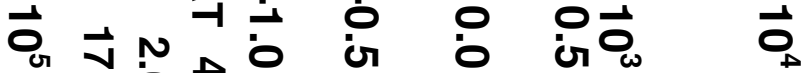

जी जि

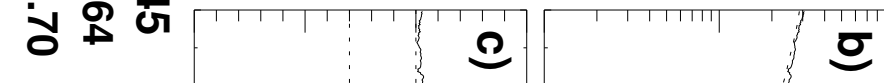

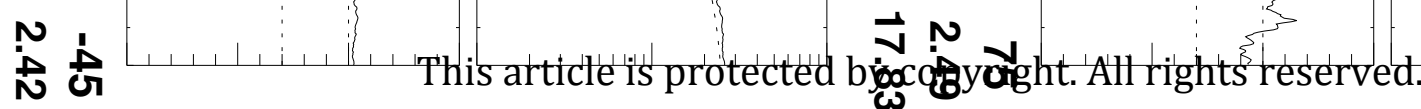


Figure 2.
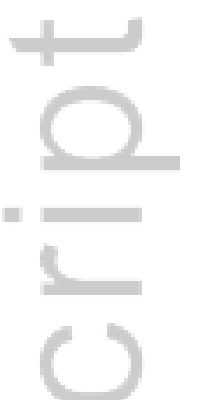

$\infty$
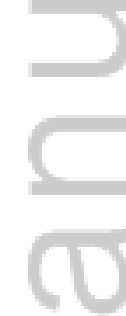

This article is protected by copyright. All rights reserved. 


Figure 5.
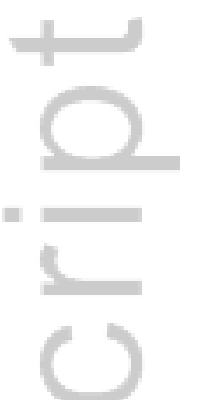

$\infty$
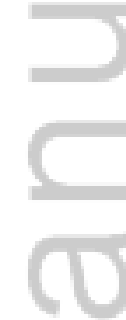

This article is protected by copyright. All rights reserved. 

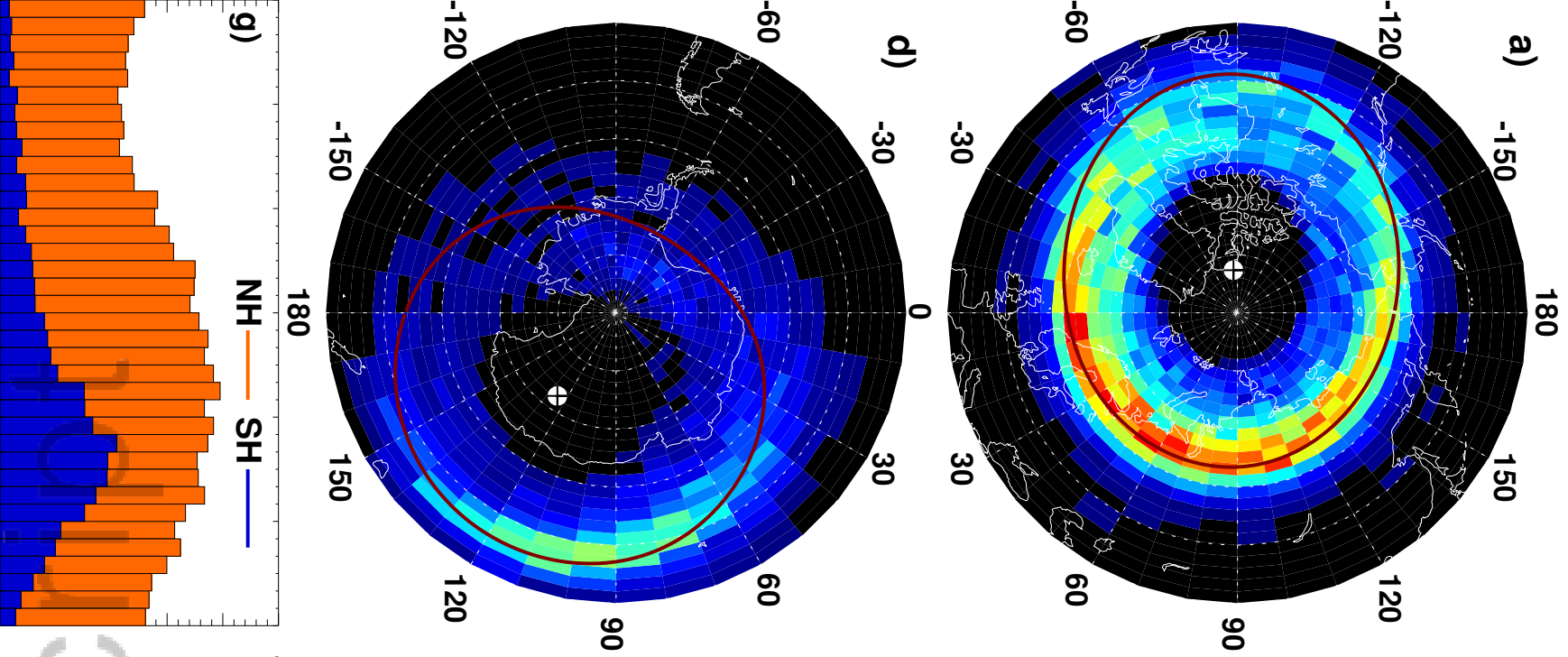

$\circ \approx$ 용 $8 \overrightarrow{8}$
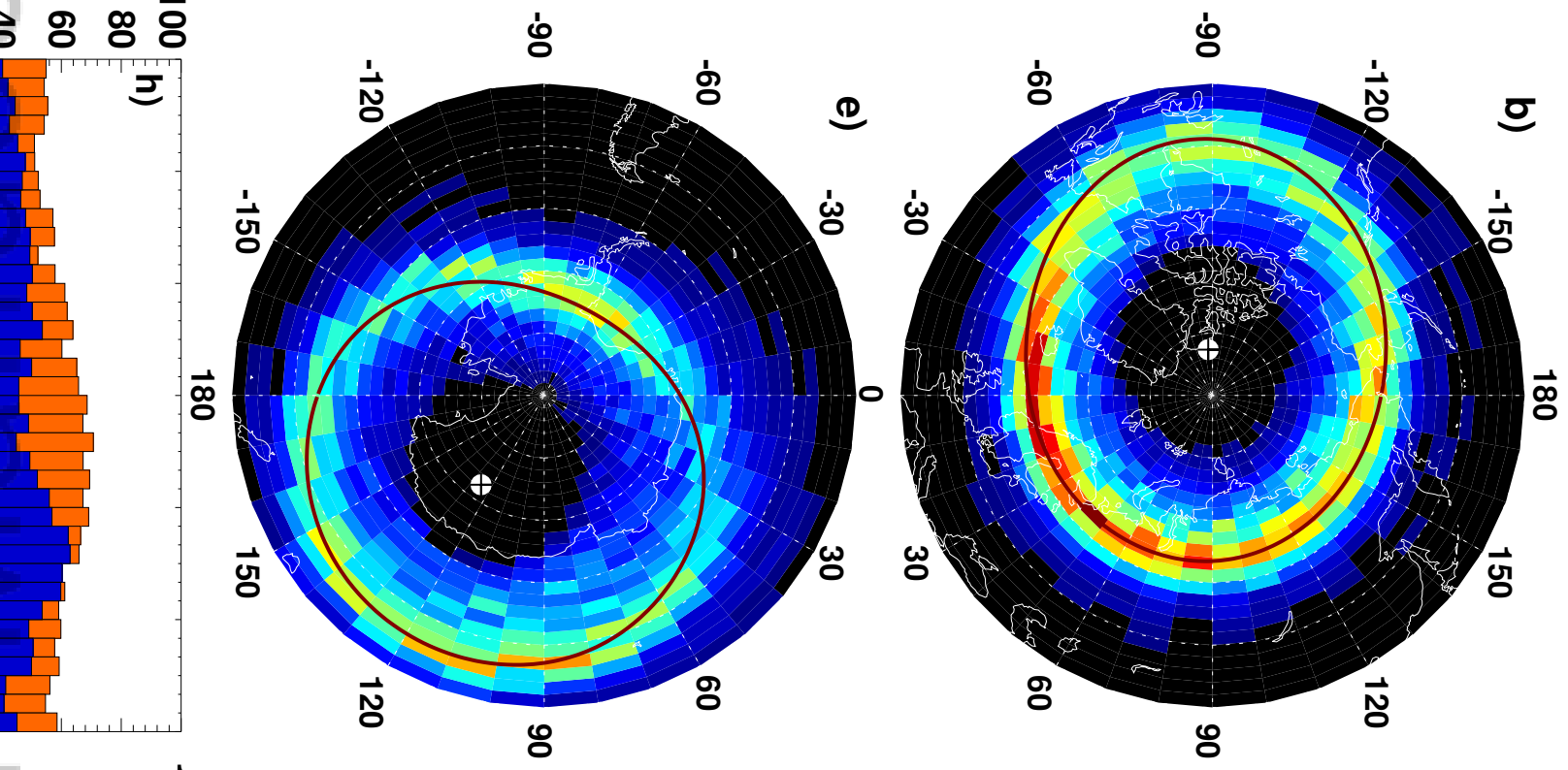

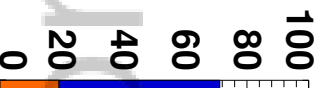
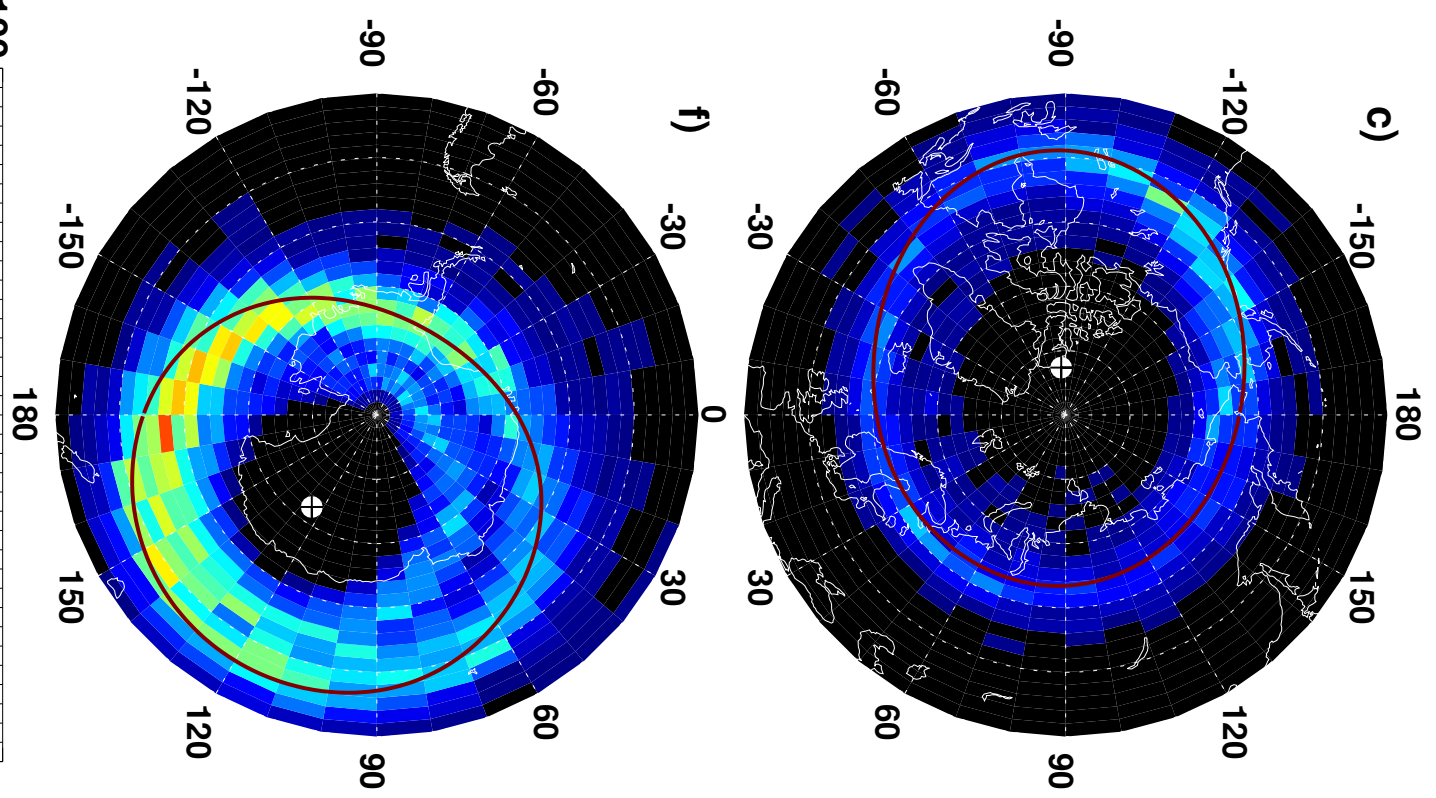

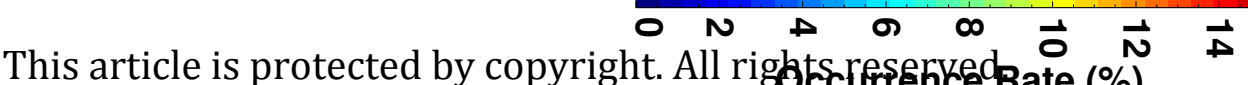

This article is protected by copyright. All rigbts respefike Rate (\%) 


\section{Degree}

Occurrence Rate (\%)

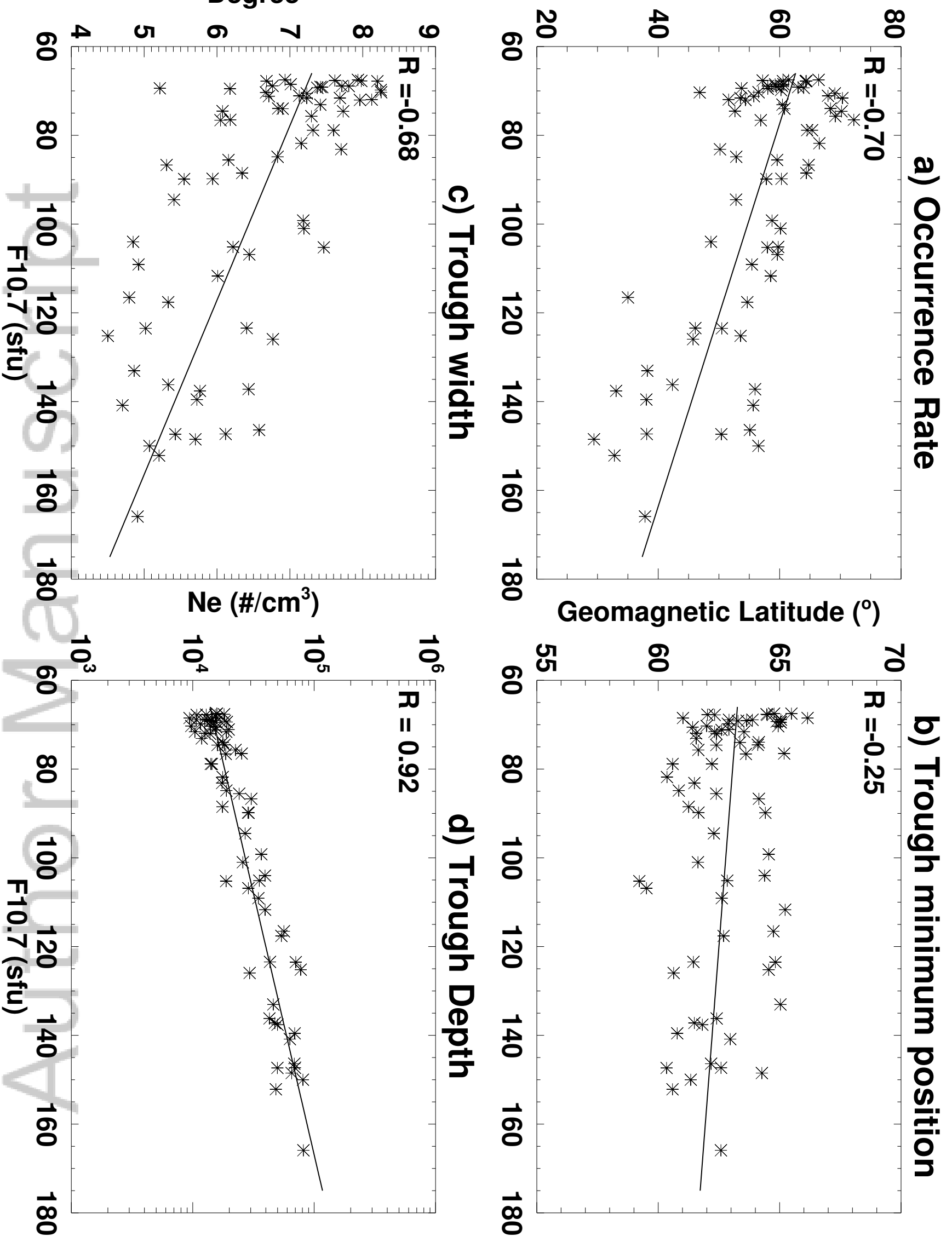

This article is protected by copyright. All rights reserved. 

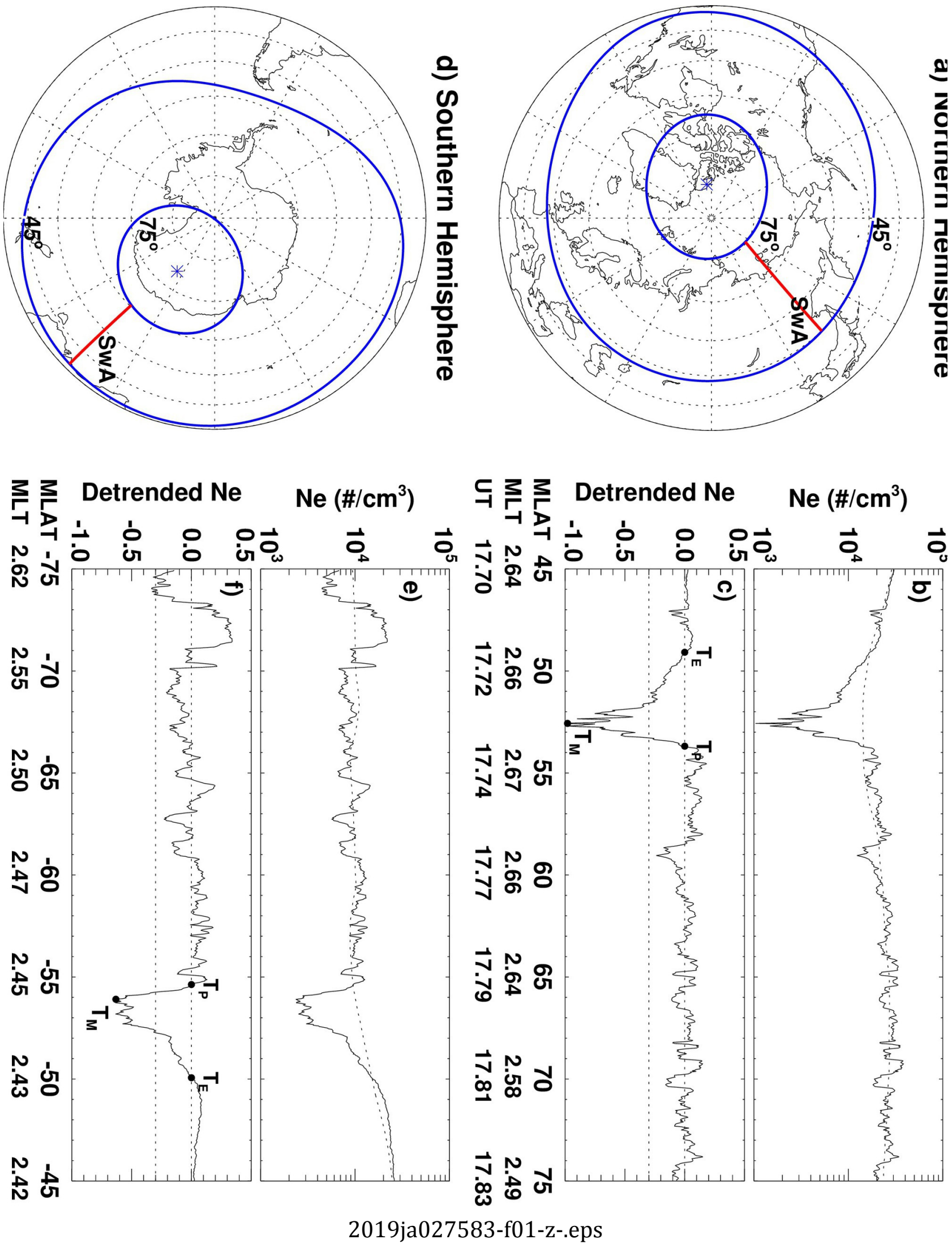

This article is protected by copyright. All rights reserved. 

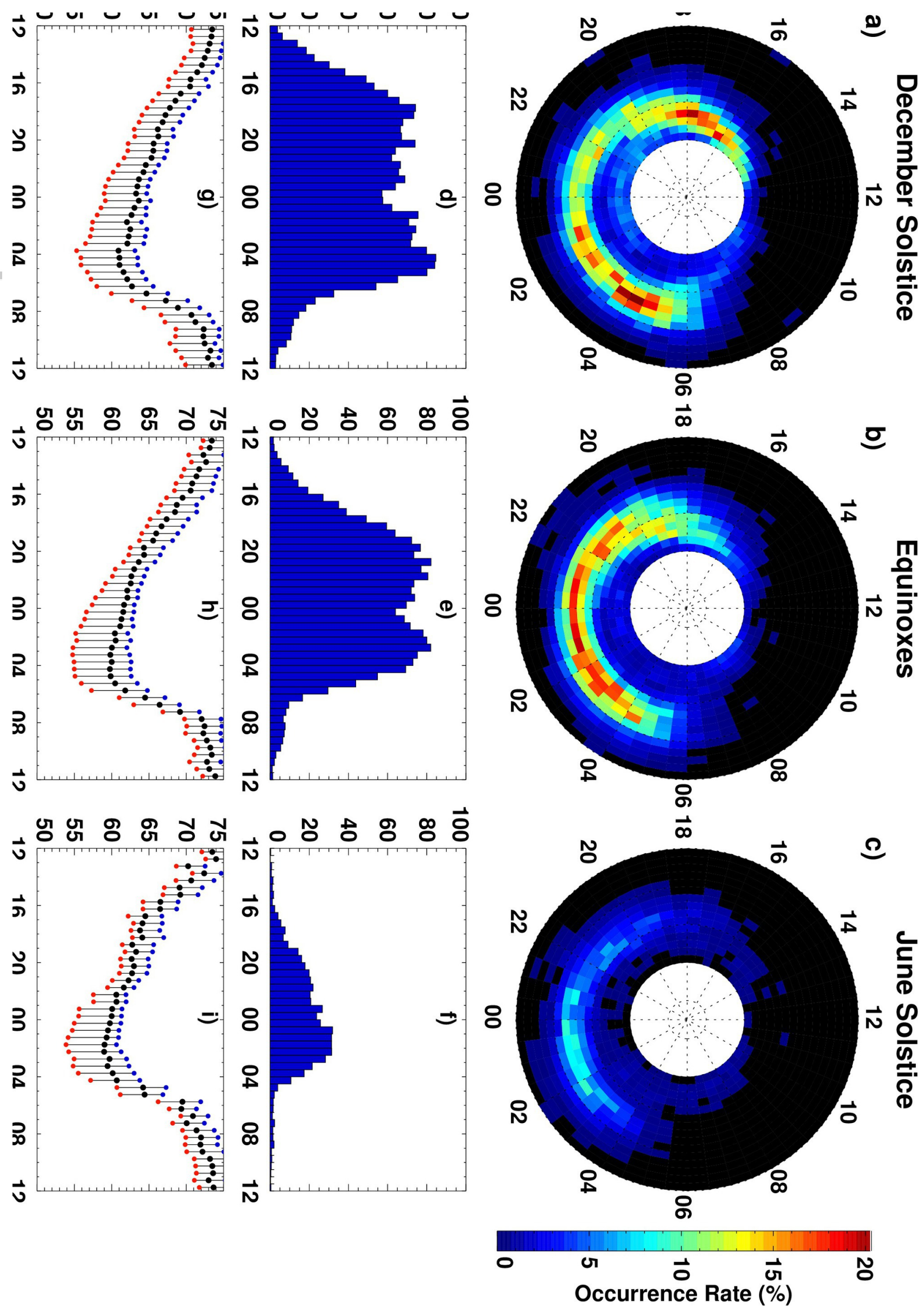

2019ja027583-f02-z-.eps 

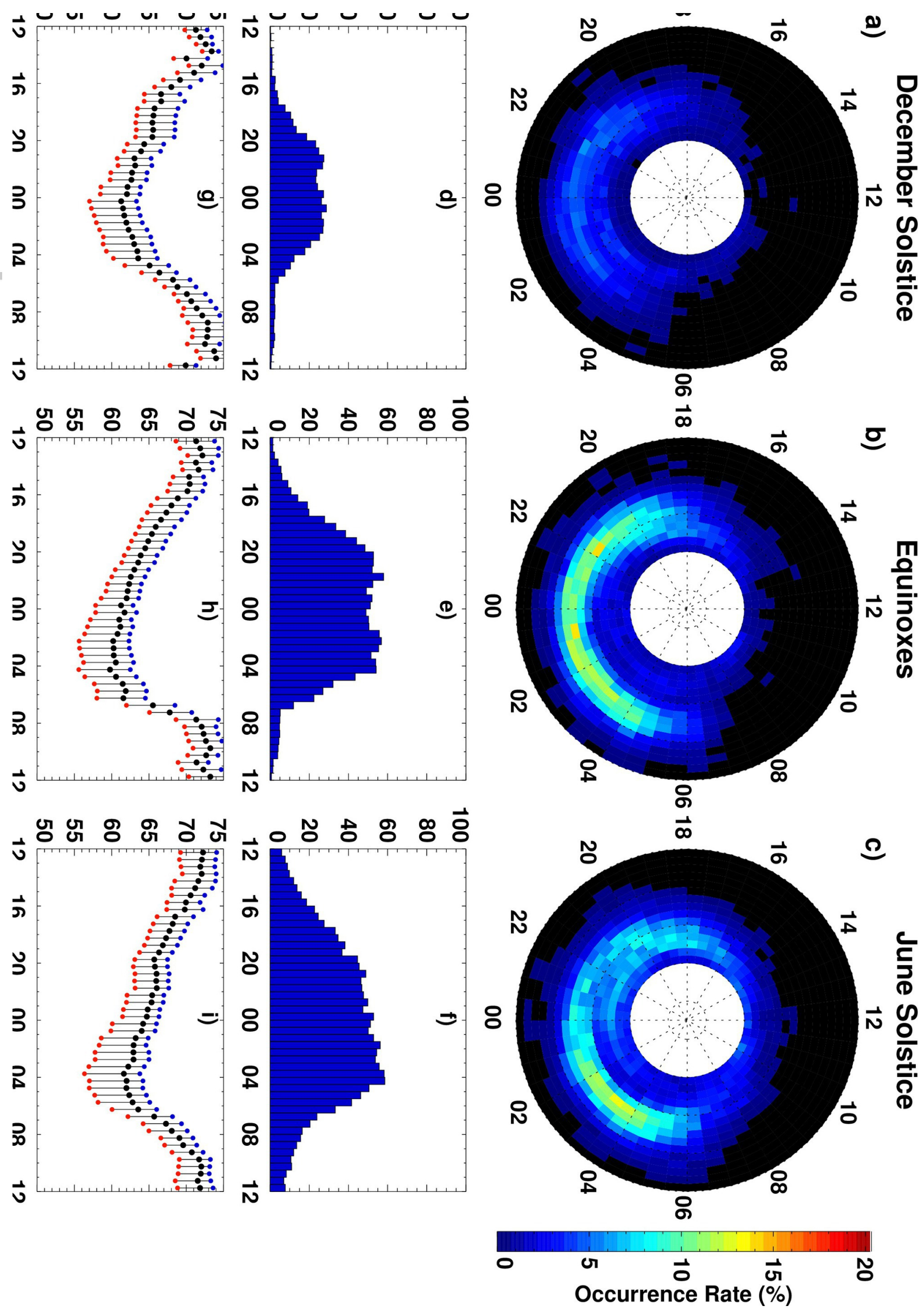

2019ja027583-f03-z-.eps 

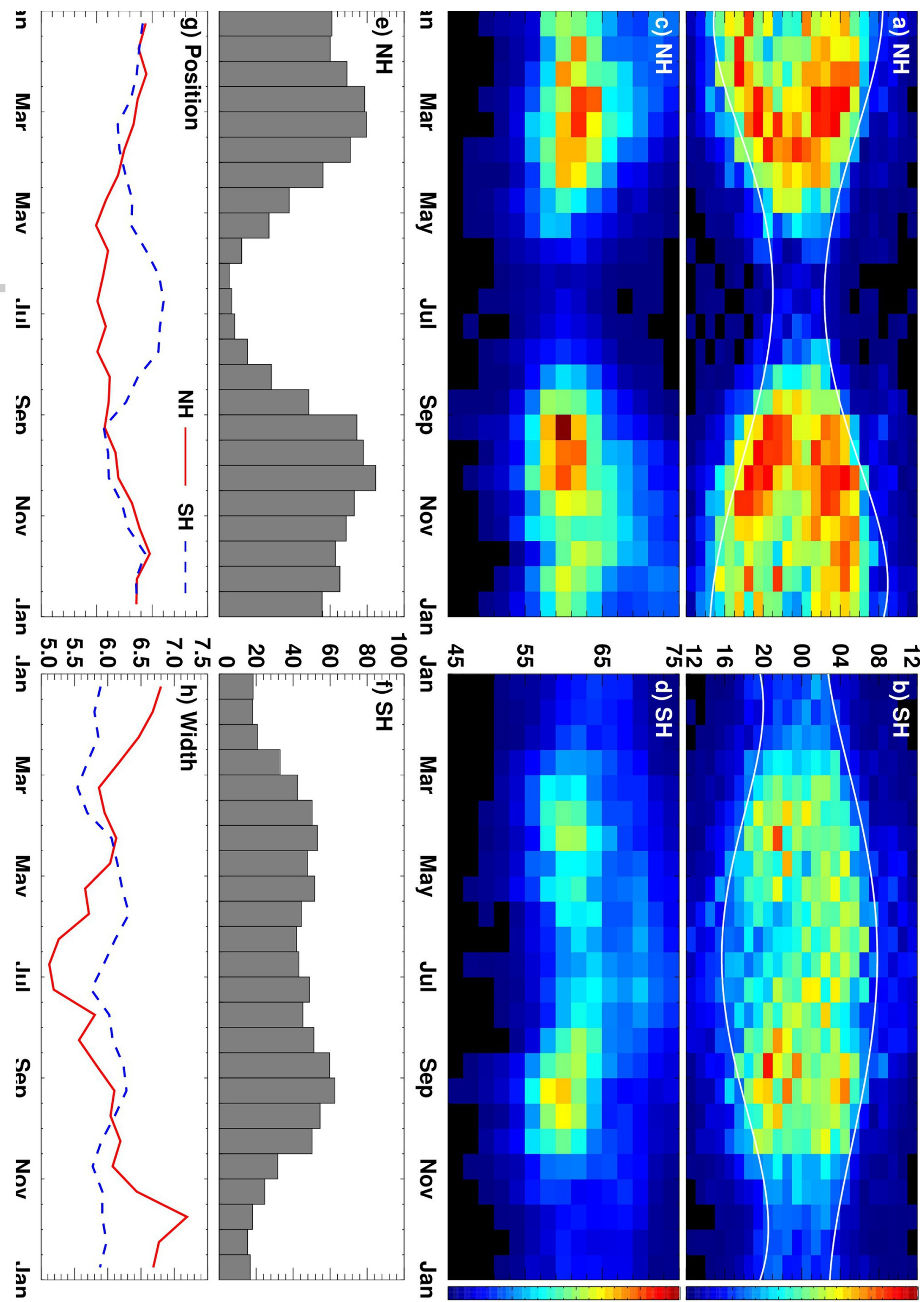

$\pm$

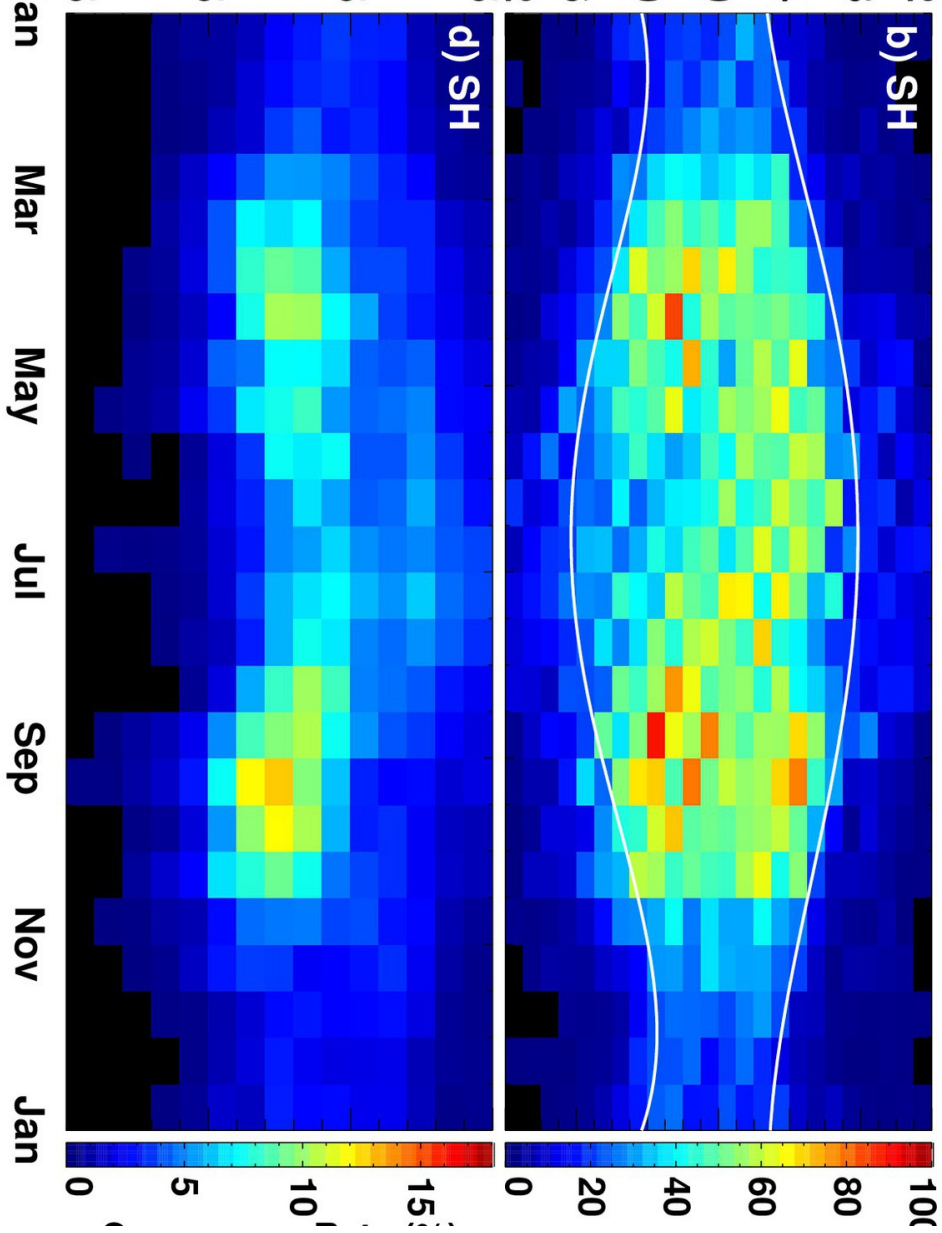

2019ja027583-f04-z-.eps

This article is protected by copyright. All rights reserved. 

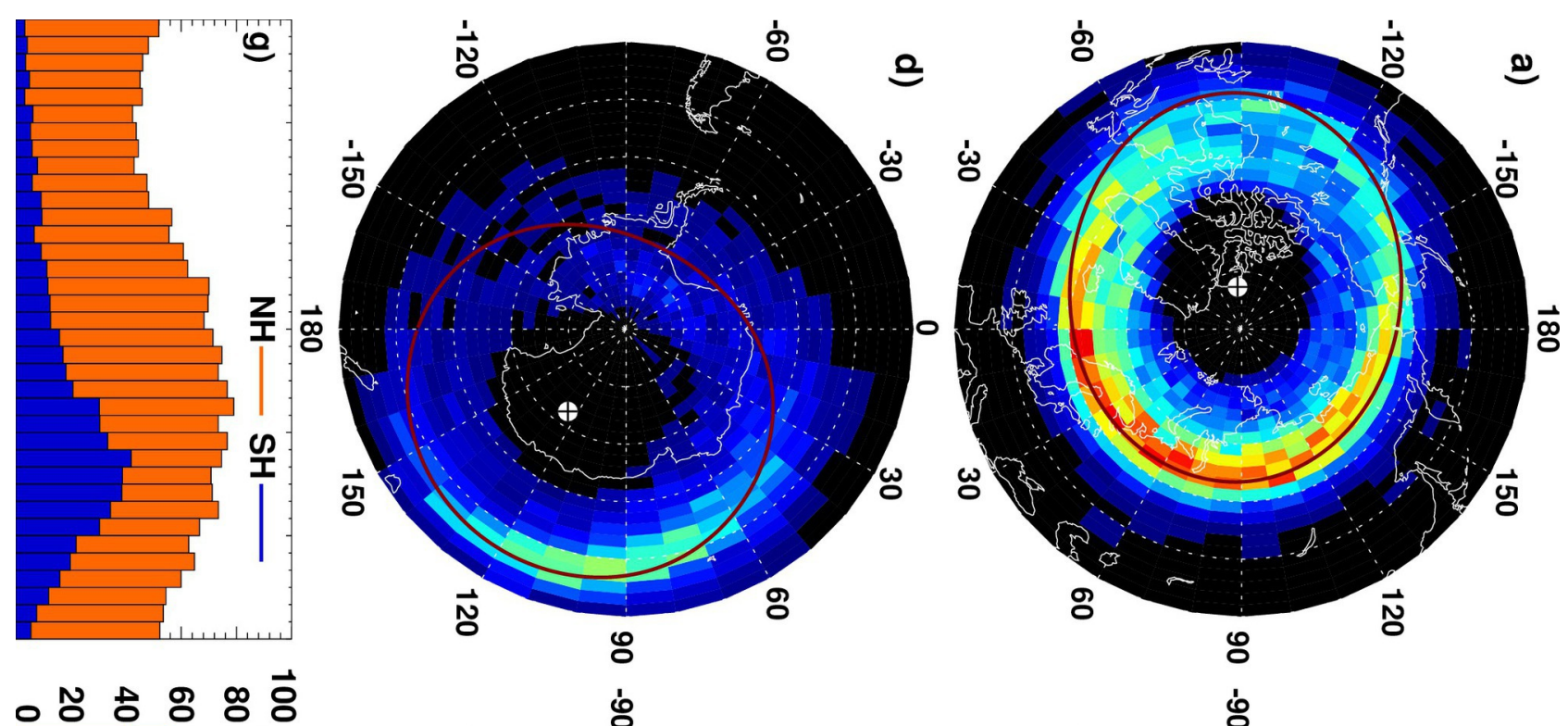

용 용 용
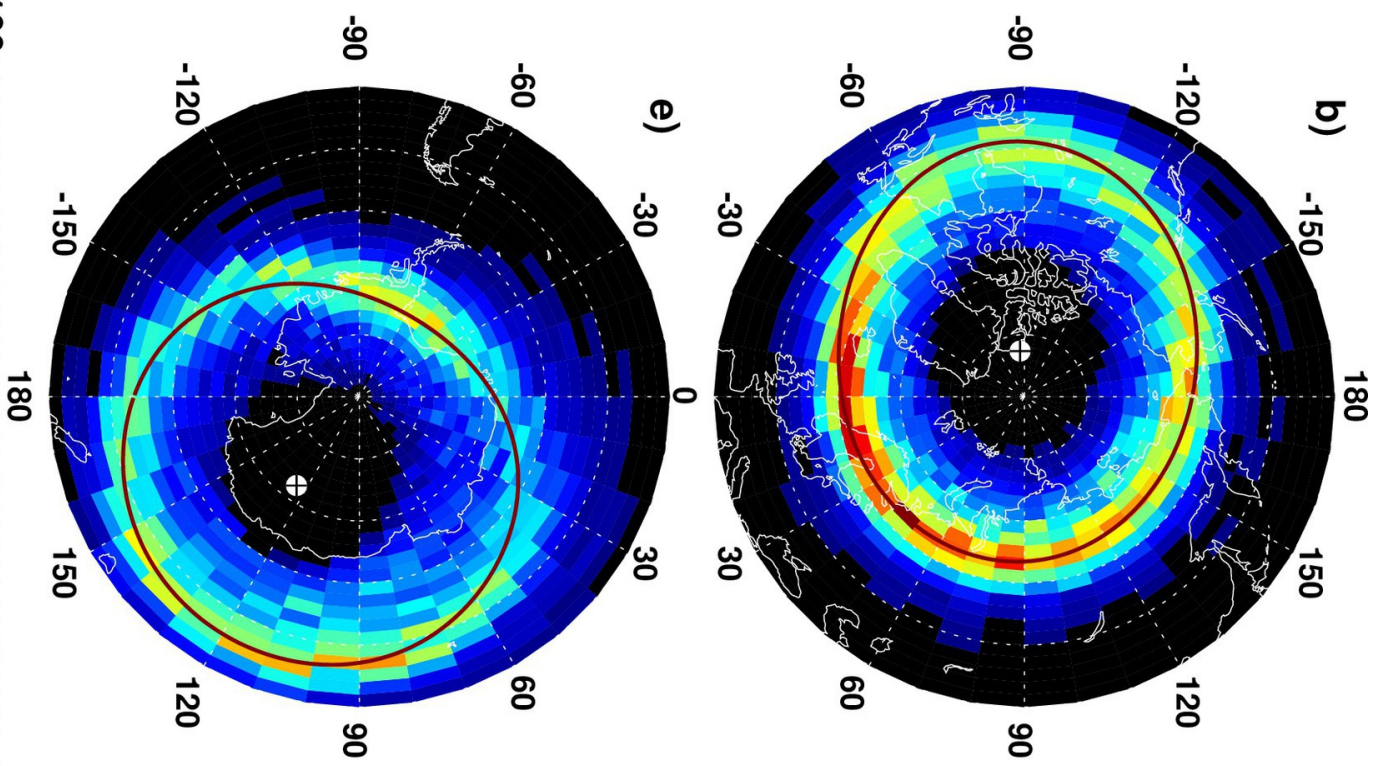

웅 효용
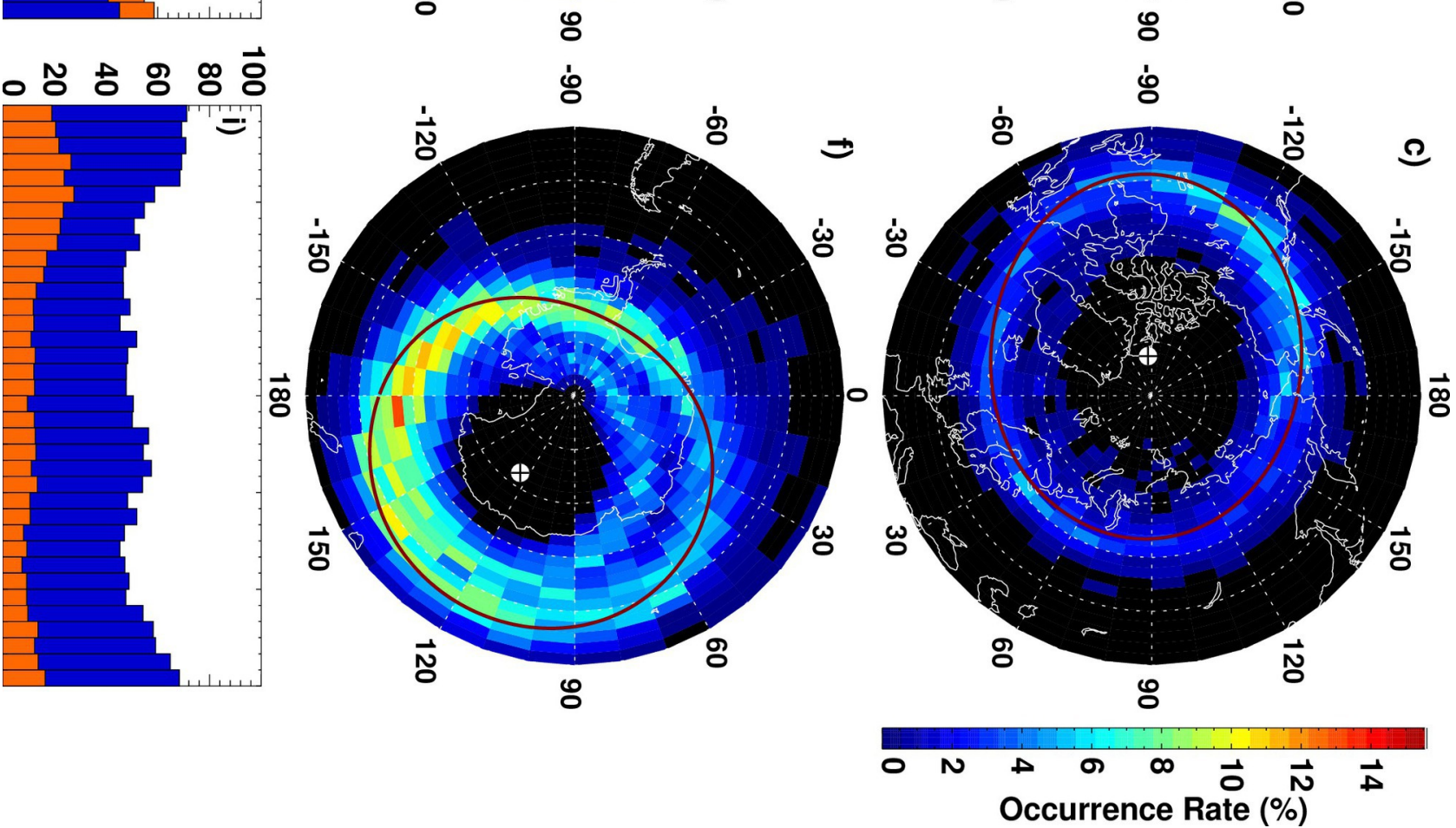

2019ja027583-f05-z-.eps 

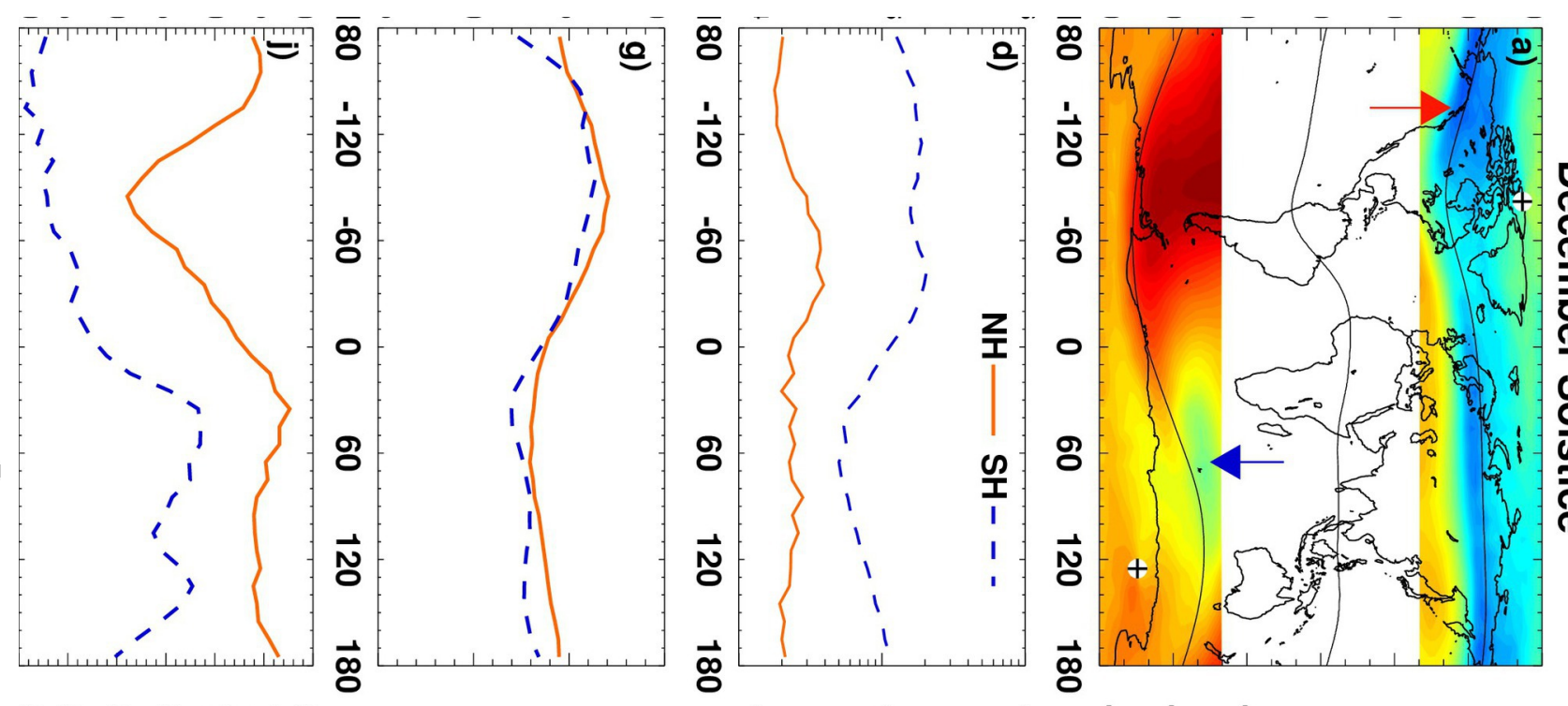

or or or
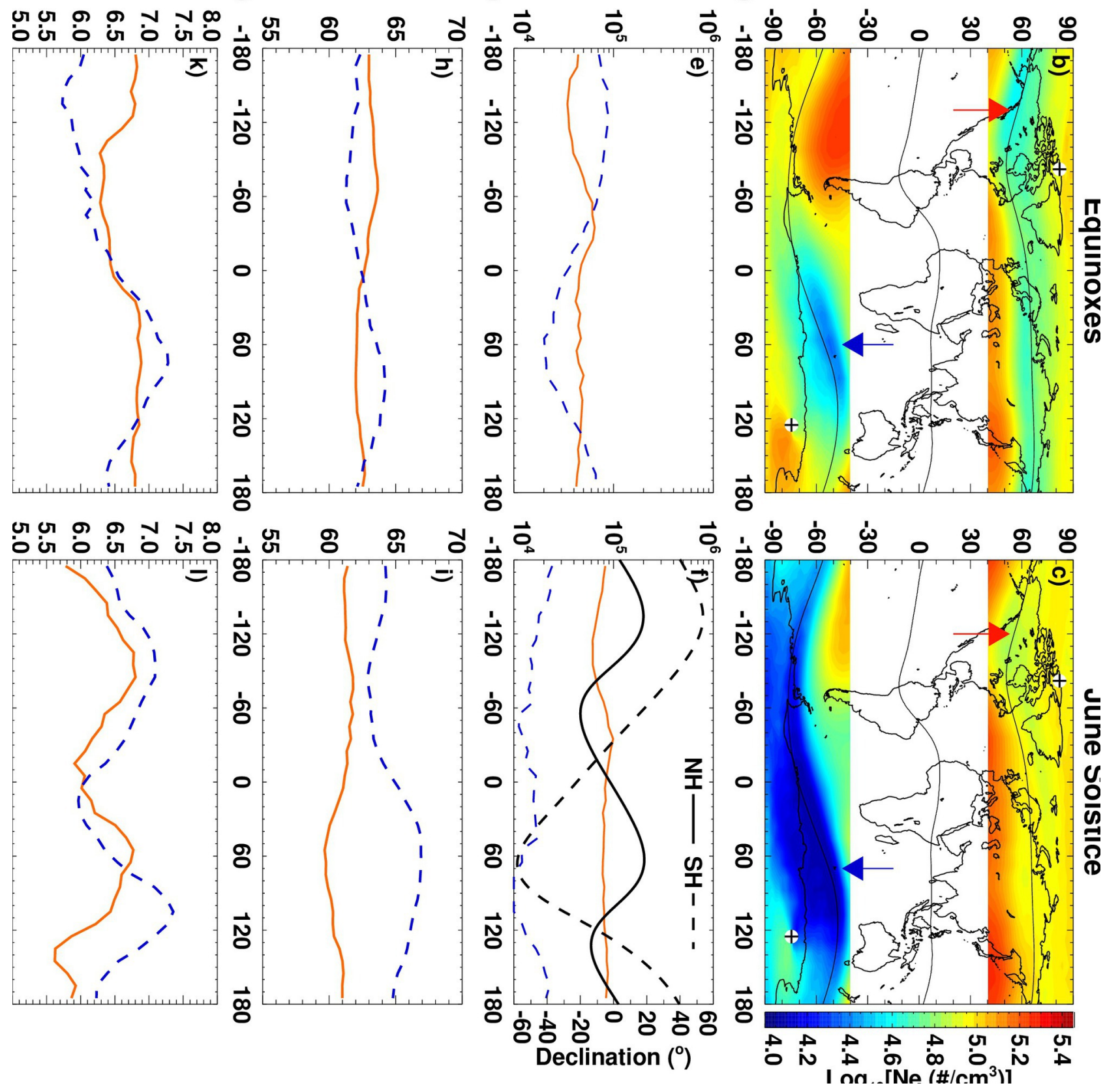

2019ja027583-f06-z-.eps 


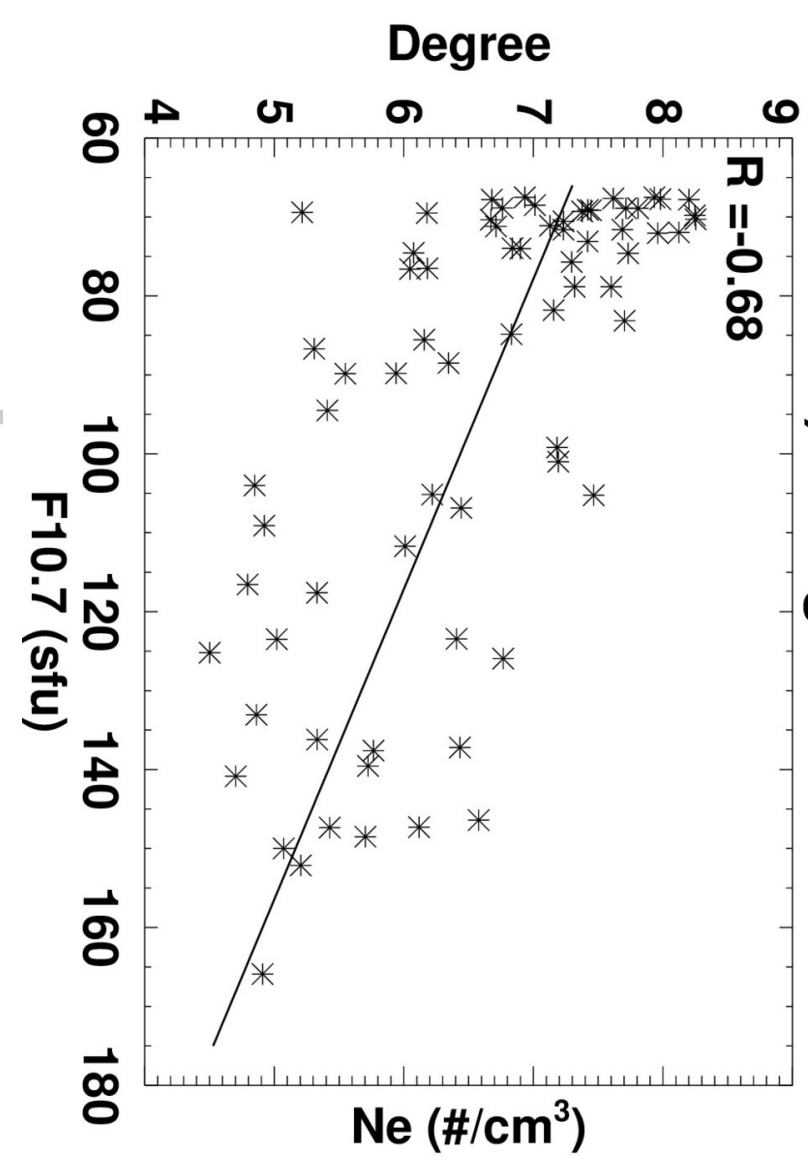

Occurrence Rate (\%)
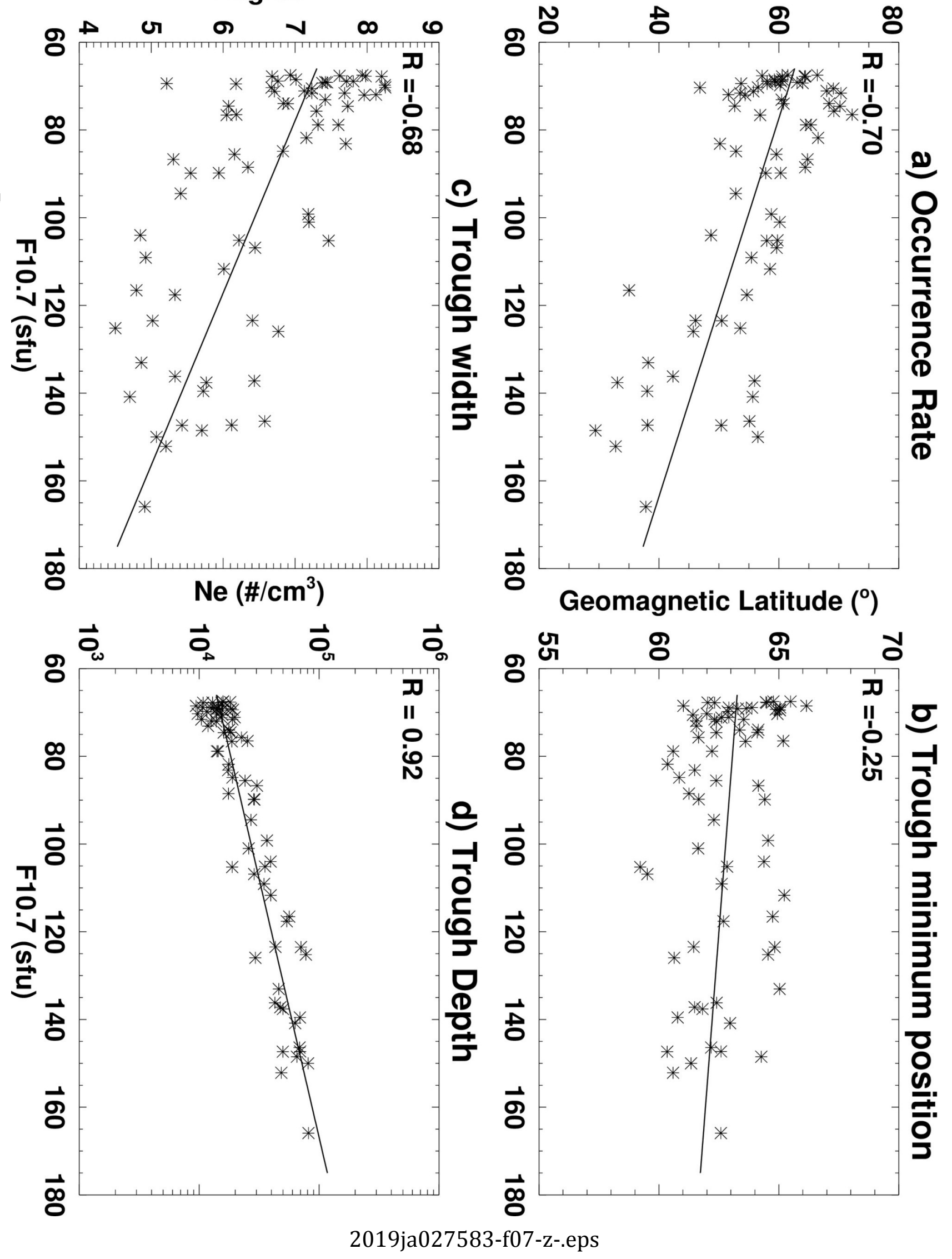

This article is protected by copyright. All rights reserved. 
Uccurrence hate (\%)

Degree $\left({ }^{\circ}\right)$

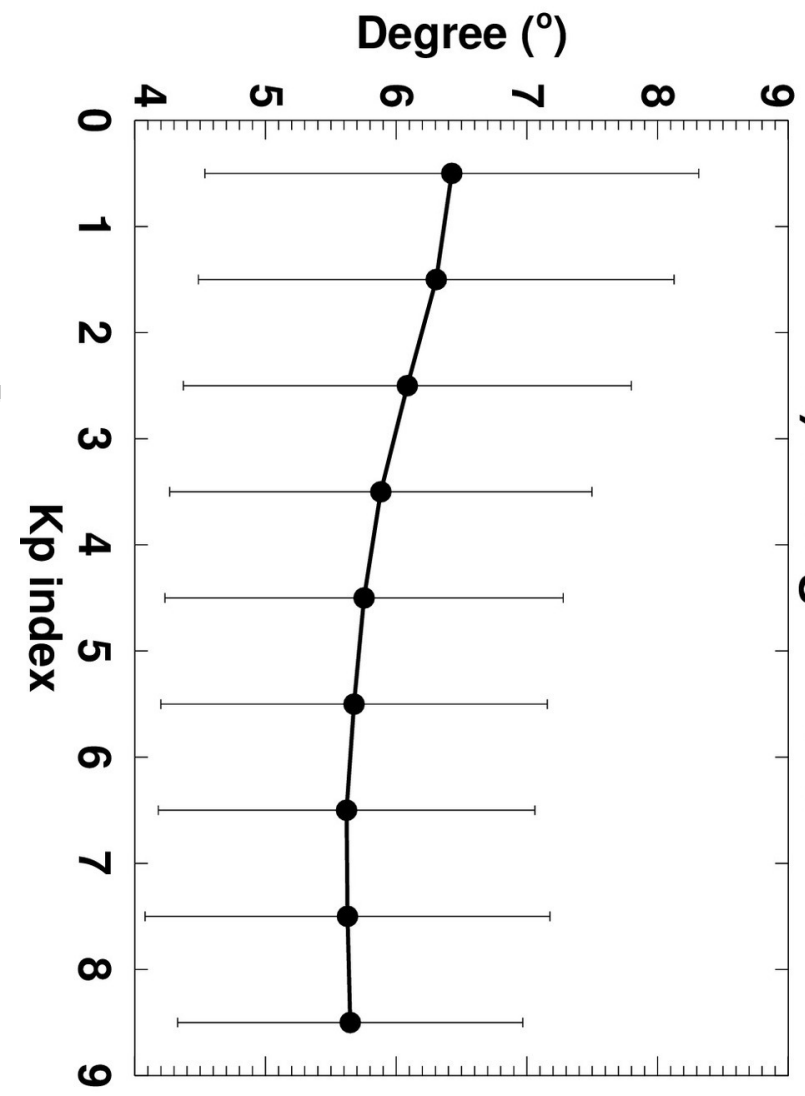

$\mathrm{Ne}\left(\# / \mathrm{cm}^{3}\right)$

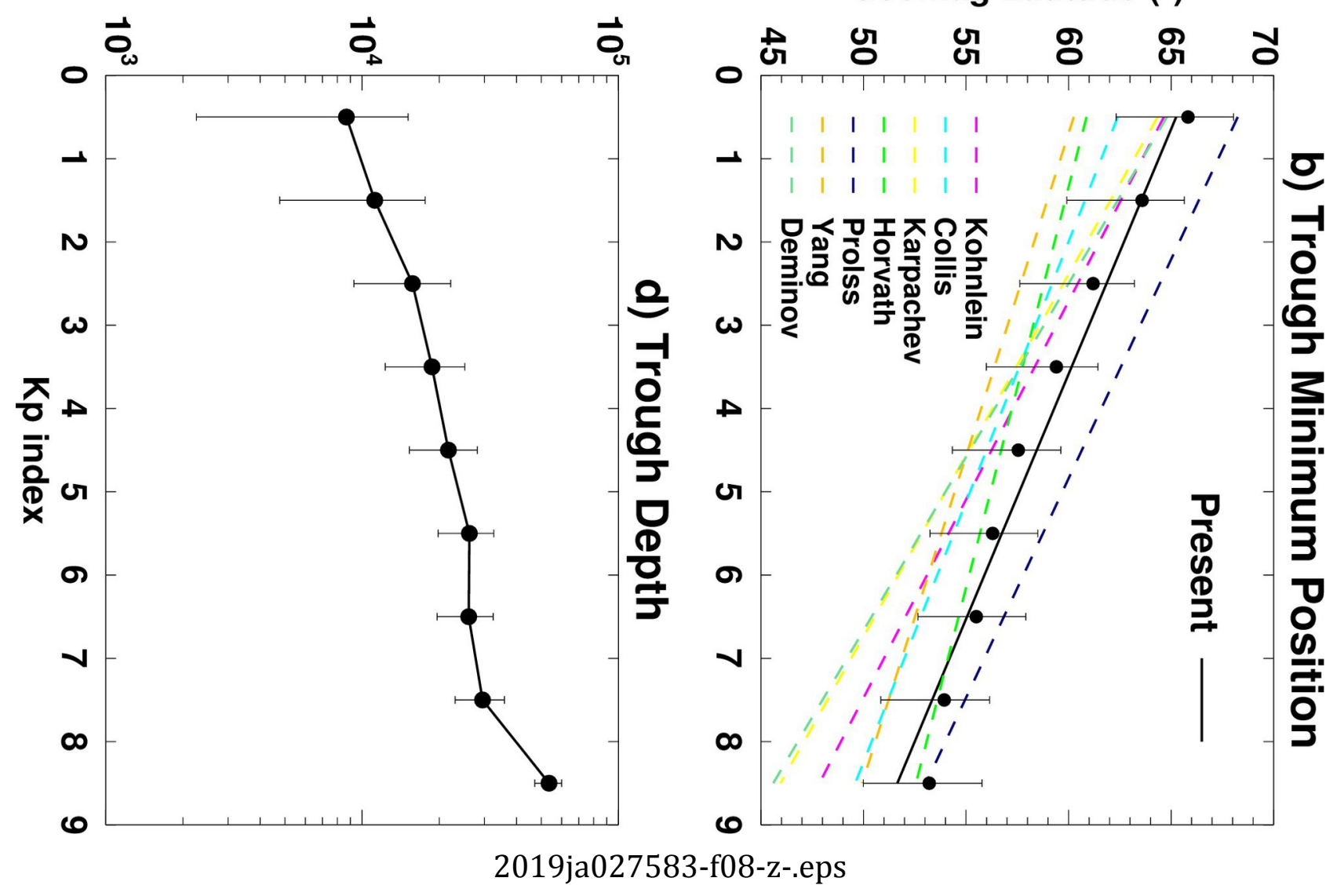

This article is protected by copyright. All rights reserved. 